\title{
HACIA LA CONQUISTA DEL NORTE: EL PROYECTO PIONERO DE FILM GRÁFICO Y LAS BATALLAS POR LA DISTRIBUCIÓN (1916-1918)
}

\section{Towards the conquest of the North: the pioneering project of Film Gráfico and the battles for distribution (1916-1918)}

\author{
Andrea Cuarterolo* \\ https://orcid.org/0000-0003-3724-1492 \\ Emiliano Jelicié** \\ https://orcid.org/0000-0003-3672-4273
}

\section{Resumen}

El fotógrafo, periodista, escritor y cineasta Alejandro Del Conte es hoy célebre por su rol fundamental en el desarrollo, difusión y profesionalización de la fotografía artística en la Argentina. Poco se sabe, sin embargo, de los variados y precursores proyectos que este personaje multifacético desarrolló en el ámbito de la producción, distribución, exhibición y, sobre todo, de la crítica cinematográfica regional. En efecto, además de exhibir, alquilar y dirigir películas en el norte del país y en Buenos Aires, en 1917 Del Conte fundó y editó en Tucumán una publicación gremial dedicada al cine, pionera y hoy casi desconocida: Film Gráfico. Revista Semanal Cinematográfica del Norte de la República. Basándonos en su correspondencia y archivo personal y en los pocos ejemplares sobrevivientes de esta publicación, en este trabajo proponemos no solo reconstruir este único y ambicioso proyecto editorial, sino también el papel que esta publicación tuvo en la creación y desarrollo de un temprano proyecto para instaurar un circuito comercial regional cuyo centro no estaba en la Capital sino en Rosario, ciudad que muy pronto se convertiría en el segundo polo cinematográfico de importancia en el país durante el período silente.

$<$ Cine regional $><$ Cine silente $><$ Primeras publicaciones de cine $><$ Distribución cinematográfica $>$

\begin{abstract}
The photographer, journalist, writer, and filmmaker Alejandro Del Conte is today well-known for his fundamental role in the development, dissemination and professionalization of artistic photography in Argentina. Little is known, however, of the varied and absolutely pioneering projects that this multifaceted character developed in the field of production, distribution, exhibition and, above all, regional film criticism. In fact, in addition to exhibiting, renting and directing films in the north of the country and in Buenos Aires, during 1917 Del Conte founded and directed an early coorporative magazine dedicated to cinema in the city of Tucumán, which is almost unknown today: the Film Gráfico Revista Semanal Cinematográfica del Norte de la República. Based on his personal correspondence and archive, and on the few surviving copies of this publication, in this work we intend to reconstruct this unique and ambitious editorial project as well as the role that this publication had in the creation and development of an early project to set up a regional commercial circuit whose center was not in Buenos Aires but in Rosario, a city that would soon become the second most important cinematographic hub in the country during the silent period.
\end{abstract}

$<$ Regional cinema $><$ Silent cinema $><$ Early cinema magazines $><$ Film distribution $>$

Recibido: 28/09/2020//Aceptado: 29/12/2020

* Consejo Nacional de Investigaciones Científicas y Técnicas (CONICET) y Facultad de Filosofía y Letras, Universidad de Buenos Aires (UBA), Argentina, acuarterolo@gmail.com

** Facultad de Artes Audiovisuales, Universidad Nacional de las Artes (UNA), Argentina, emilianojelicie@gmail.com 
Cuarterolo y Jelicié. Hacia la conquista del Norte: el proyecto pionero de Film Gráfico y las batallas por...

\section{Introducción ${ }^{1}$}

El fotógrafo, periodista, escritor y cineasta Alejandro Del Conte es hoy célebre por su rol fundamental en el desarrollo, difusión y profesionalización de la fotografía artística en la Argentina. Fundador y promotor de notables instituciones fotográficas del país y del exterior, autor de importantes manuales y tratados técnicos sobre fotografía, retratista consagrado en numerosos salones internacionales y destacado docente, ${ }^{2} \mathrm{su}$ obra más recordada es, sin duda, la fundación en 1921 de la emblemática revista Correo Fotográfico Sudamericano. Desde sus páginas impulsó a grandes y heterogéneos fotógrafos artísticos de la época como Annemarie Heinrich, Anatole Saderman, Hiram Calógero, Humberto Zappa o Pedro Otero. Poco se sabe, sin embargo, de los variados y precursores proyectos que este personaje multifacético desarrolló en el ámbito de la producción, distribución, exhibición y, sobre todo, de la crítica cinematográfica regional. En efecto, además de exhibir, alquilar y dirigir películas en el norte del país y en Buenos Aires, en 1917 — con tan solo 19 años- Del Conte fundó y editó en Tucumán una publicación gremial dedicada al cine, pionera y hoy casi desconocida, llamada Film Gráfico. Revista Semanal Cinematográfica del Norte de la República. Basándonos en su correspondencia, en su archivo personal y en los pocos ejemplares sobrevivientes de esta publicación, la mayoría de ellos hoy conservados en un acervo privado, ${ }^{3}$ en este trabajo proponemos no solo reconstruir este único y ambicioso proyecto editorial, sino también el papel que esta revista tuvo en la creación y desarrollo de un temprano, y hasta ahora inexplorado, proyecto de instaurar un circuito comercial regional cuyo centro no estaba en la Capital, sino en Rosario, ciudad que muy pronto se convertiría en el segundo polo cinematográfico de importancia en el país durante el período silente.

1 Este trabajo fue posible gracias a la indispensable colaboración del Centro de Investigación Fotográfico Histórico Argentino CIFHA (www.cifha.org.ar), que conserva gran parte del archivo personal de Alejandro Del Conte. Agradecemos muy especialmente a Alfredo Srur, su director, por abrirnos las puertas a esta colección, actualmente en proceso de catalogación.

2 Del Conte fue gestor e impulsor de la Federación Argentina de Fotografía y de otras tempranas asociaciones profesionales de nuestro medio. Asimismo, fomentó la creación y desarrollo de algunos de los primeros fotoclubes, peñas y sociedades fotográficas del interior del país, Latinoamérica y Estados Unidos, siendo a su vez distinguido con títulos honoríficos en muchas de estas instituciones. Con el propósito de "dotar a los países de América Latina de una literatura fotográfica propia, hasta ahora ausente" (Del Conte, 1939, p. 7) fundó, en el marco del Correo Fotográfico Sudamericano, una editorial especializada en la confección de importantes manuales y libros técnicos en español. Entre las publicaciones de su autoría que formaron parte de esta colección se encuentran Formulario fotográfico (1939), Ampliaciones fotográficas. Técnica y recursos (s.f.) y La fotografía de los colores (1944). A partir de 1925 también editó un suplemento de distribución callejera destinado a la divulgación popular de la fotografía, llamado Chasirete. Asimismo, en 1936, instaló una galería y varios laboratorios fotográficos experimentales en un anexo de la redacción del Correo Fotográfico Sudamericano y creó allí una escuela de fotografía que funcionó gratuitamente. Véase Friedman (1952) y Polacow (1952).

3 En el CIFHA se conservan 15 de los 23 números de Film Gráfico publicados en 1917. Agradecemos al investigador tucumano Ricardo A. Brunetti, quien nos facilitó un ejemplar de esta publicación perteneciente a su colección que faltaba en el archivo del CIFHA. Véase Brunetti (2016). 


\section{Alejandro Del Conte, un pionero desconocido del cine regional}

En uno de los tantos obituarios que inundaron las páginas de las publicaciones fotoclubísticas latinoamericanas, luego de la prematura muerte de Alejandro Del Conte en 1952, el fotógrafo y periodista Jacobo Polacow (1952) confesaba su dificultad para discernir "en cuál de los múltiples sectores de su actividad [éste] se realizó con más plenitud, si como periodista, como divulgador del arte de la cámara, como crítico, como artista o como incentivador de la vida asociativa y clubística de los aficionados de la fotografía", pero afirmaba con certeza que si Del Conte "había trabajado exhaustivamente por la fotografía, no lo había hecho menos por el cine de su tierra" (p. 8). En efecto, aunque esta última faceta de su trayectoria se ha visto opacada con los años por su actividad fotográfica, el acceso a nuevas fuentes hoy vuelve necesario reconstruir su sostenida y absolutamente pionera trayectoria en el campo de la temprana cinematografía argentina $\mathrm{y}$, sobre todo, su fundamental papel en el desarrollo de la cultura cinematográfica en el norte del país.

Alejandro Del Conte nació en 1897, en Buenos Aires. Con apenas 16 años de edad, mientras aún se encontraba cursando sus estudios secundarios en el Colegio Nicolás Avellaneda, inició su carrera periodística colaborando en la popular revista $P B T$, donde tuvo la oportunidad de compartir los salones de la redacción con grandes plumas de la época como Eustaquio Pellicier, Natalio Botana, José Pacífico Otero o José María Aguado de la Loma. Entre 1913 y 1916, publicó en las páginas de este emblemático semanario decenas de reportajes, artículos costumbristas y notas de actualidad que firmaba ya sea con su nombre o con el pseudónimo de "Juan Porteño". En 1916, "ávido de nuevos horizontes como correspondía a su espíritu inquieto" (Friedman, 1952, p. 8), Del Conte viajó a San Miguel de Tucumán con el propósito de incursionar en el negocio de la exhibición teatral y cinematográfica. Sin experiencia previa en el rubro, no se abocó al cine de entrada, sino que comenzó gestionando espectáculos de variedades ${ }^{4}$ en diversos teatros y salones norteños donde también se ofrecían proyecciones de cinematógrafo y música en vivo, manteniendo ambas actividades durante la mayor parte de su estadía en la ciudad. Estas primeras tareas como agente artístico resultan significativas, porque sugieren que la explotación de cintas no estaba en sus planes cuando viajó a Tucumán y fue recién allí donde pudo vislumbrarla como una actividad factible y redituable. El hecho de que los números de varieté se alternaran con la exhibición de películas en programas por secciones indica que, en esta ciudad, había un funcionamiento similar al que se mantenía en los salones populares de grandes urbes como Buenos Aires, Córdoba y Rosario. Seguramente ese vínculo estrecho entre ambas formas de espectáculo hacía que el pasaje de una actividad a otra se volviera natural y perfectamente combinable. Cabe recordar, además, que la crisis de importación provocada por la Primera

\footnotetext{
${ }^{4}$ El primer contrato del que se tiene registro se habría llevado a cabo en el Majestic Palace de la capital tucumana, según se desprende de una carta de Eduardo Manella, propietario de la Agencia Teatral Internacional de Buenos Aires. Este le ofrece comprar los derechos de una cantante y bailarina apodada "La Chispita" con el fin de "hacerla trabajar en primera sección", esto es, "dos antes de biógrafo", y "después mandarla a Salta, Santiago y algún otro sitio", lo que da una idea de cómo funcionaban los espectáculos por secciones de la época. Véase "Carta de Eduardo Manella (Buenos Aires) a Alejandro Del Conte (Tucumán)”, 14 agosto de 1916, CIFHA.
} 
Cuarterolo y Jelicié. Hacia la conquista del Norte: el proyecto pionero de Film Gráfico y las batallas por...

Guerra Mundial y la consecuente escasez de novedades fílmicas en los programas había sido, por ese entonces, uno de los factores que obligó al retorno de los números vivos. En última instancia, el teatro, la música y el cine compartían un mismo espacio edilicio, como son en este caso el cine-teatro y el cine-casino, dos tipos de emplazamientos que ya formaban parte del paisaje urbano argentino desde principios de 1910.

En enero de 1917, ya asentado en Tucumán, Del Conte alquiló el viejo teatro Belgrano, que para esa fecha se encontraba en franca decadencia y contaba con apenas 236 butacas. ${ }^{5}$ La inauguración de dos nuevas e importantes salas en 1912 (el Odeón y el Alberdi) había sido un duro golpe para este histórico coliseo que, luego de décadas de sucesivos arriendos, se encontraba cada vez más necesitado de refacciones que se postergaban a pesar de su urgencia. El contrato que firmó, en enero de 1917, con Julio Alberto Castillo, establecía el alquiler del Belgrano con todo su inventario por el término de un año, a cambio del pago de un diez por ciento de la entrada bruta de todas las funciones o fiestas que se realizaran en dicha sala. ${ }^{6}$ Si bien Del Conte finalmente subarrendó este teatro $^{7}$ y no llegó a explotarlo comercialmente, durante gran parte de 1917 este edificio, ubicado a dos cuadras de la céntrica Plaza Independencia, se convirtió en el núcleo de operaciones de las múltiples y variadas actividades desarrolladas durante su estadía en Tucumán, no solo en el ámbito de la exhibición, sino también en el de la producción, la distribución y la crítica cinematográfica.

Fue sin dudas en este último campo donde Del Conte llevó a cabo su proyecto más relevante: la fundación de Film Gráfico, primera publicación del gremio cinematográfico de las provincias del norte del país. Lanzada en enero de 1917, apenas tres años después que la porteña Excelsior (la revista especializada en cine más antigua de la Capital) y casi un año antes que la rosarina Cinema Star (cuyo primer número data del 29 de noviembre de 1917), Film Gráfico constituye una de las primeras publicaciones cinematográficas editadas en el interior del país, superada tan solo por la rosarina Cinema, fundada en junio de 1911 por el empresario Juan Lluch. ${ }^{8}$ Se trata, por tanto, de un proyecto editorial señero,

5 Este imponente coliseo, que originalmente tenía "una capacidad de 1.500 personas" (Colombres y Piñero, 1901), había sido edificado en 1878 por una Sociedad Anónima de tucumanos que no administraba directamente la sala, sino que la arrendaba. En 1887, ante el acelerado deterioro del edificio, la Provincia cedió a la Municipalidad las acciones que poseía y, con ese paquete y las acciones que le donaron los particulares, ésta se convirtió en dueña del teatro (Páez de la Torre, 2018).

6 "Contrato entre Julio Alberto Castillo y A. Del Conte por alquiler del Teatro Belgrano", Tucumán, 15 de enero de 1917, CIFHA.

7 Del Conte anuncia su decisión de subarrendar el Belgrano a Juan B. Orti en abril de 1917, cambiando la dirección postal de su revista, antes ubicada en el teatro ("El Belgrano. Su reapertura", Film Gráfico n. 7, 21 de abril de 1917, p. 2).

8 Maldonado (2006) menciona la existencia en Tucumán de una publicación anterior llamada El Espectador. Esta información surge de una nota publicada en el diario La Tribuna de dicha ciudad, que en su edición del 18 de octubre de 1916 anuncia una "interesante revista que se ocupa especialmente del movimiento de Cines en nuestra capital y en el interior de la república" (Maldonado: 2006, p. 34). Teniendo en cuenta que no hemos encontrado ninguna mención a esta publicación en otras fuentes de época, que para esta fecha Del Conte ya se encontraba en Tucumán y que el primer número de su revista se publicó apenas tres meses después, en enero de 1917, es posible suponer que este artículo se refiere justamente a la inminente publicación de Film Gráfico, que probablemente adquirió su título definitivo después de este anuncio. De 
sobre todo en una región como el NOA, donde el gremio cinematográfico era, por entonces, casi inexistente. En ese sentido, la revista no fue para Del Conte un mero agregado por acumulación de los múltiples proyectos que desarrolló en esta región, sino que funcionó como un espacio de integración y amplificación de sus demás actividades, un intento por organizar esquemas de negocios en una zona donde todavía no existía un sistema bien articulado y estable, en buena medida porque las grandes empresas alquiladoras de la ciudad de Buenos Aires no depositaban expectativas comerciales en ella.

De hecho, Del Conte utilizó a la revista como una plataforma desde la cual lanzó su propia empresa de distribución en la región norte del país. Ya en el segundo número de Film Gráfico, su administrador Eduardo Grignolino anunciaba la apertura de una "oficina adscripta a este periódico para informes, alquiler y explotación de películas", 9 transparentando la estrecha relación entre ambos negocios. A partir de ese momento, se multiplicaron los avisos de películas nacionales y extranjeras distribuidas en la zona a través de la revista. Del Conte se dedicó de lleno a intermediar entre las compañías alquiladoras y los exhibidores norteños. Por un lado, recibía las noticias sobre la disponibilidad, condiciones y precios de las cintas que solicitaba a Buenos Aires o a Rosario; por el otro, atendía los pedidos de los exhibidores de Tucumán y las provincias aledañas. En cuanto al primer tipo de intercambio, fue la Cooperativa Biográfica la compañía alquiladora que acaparó la mayor parte de sus solicitudes. Esto no quiere decir que no haya trabado contacto con otras empresas pero, como veremos más adelante, es evidente que fue la alquiladora de Manuel Brugo, que además era anunciante de la revista, la que más perduró en su "gestión como representante". ${ }^{10}$

Si bien su trayectoria en el campo de la producción fílmica fue breve, espaciada y comparativamente menor a la de sus actividades en otras ramas del mercado cinematográfico, sus dos incursiones en el cine también merecen, por su importancia para la región y por su carácter absolutamente pionero, una descripción más detallada. En efecto, poco después de su llegada a Tucumán, Del Conte fue responsable de uno de los principales hitos cinematográficos del NOA al realizar el que muy probablemente sea el primer film surgido de la región ${ }^{11}$ : Tucumán durante las Fiestas del Centenario (1916). Varios de los obituarios publicados con motivo de su fallecimiento ${ }^{12}$ hacen referencia a su participación en esta cinta, cuya singularidad era que documentaba uno

todas maneras, queda abierto el interrogante para futuras investigaciones.

9 "Habla el administrador", Film Gráfico, n. 2, 10 de febrero de 1917, p.1.

10 "Carta de Eduardo Grignolino (Tucumán) a Alejandro Del Conte (Buenos aires), 27 de mayo de 1918, CIFHA.

${ }^{11}$ Esta afirmación se desprende del relevamiento y la base de datos filmográficos que venimos realizando en el marco del proyecto PICT "Cartografía y estudio histórico de los procesos cinematográficos en Argentina (1896-2016)" desde 2016.

${ }^{12}$ Véase por ejemplo Friedman (1952) y Polacow (1952). Varias de las múltiples reseñas publicadas en ocasión del estreno de su segundo film, La barra de Taponazo (Del Conte, 1932), también mencionan este antecedente filmográfico. Véase, por ejemplo: "Alejandro Del Conte filma una película para la S.A.C.H.A. Manzanera", El Mundo, 15 de agosto de 1931; "Varias cintas prepara la Manzanera, La Opinión, 15 de agosto de 1931; “'La barra de cañonazo' (sic) titulase una nueva cinta local”, La Razón, 15 de agosto de 1931; "La barra de cañonazo (sic), producción nacional", El Exhibidor, 30 de agosto de 1931, entre otros. 
de los sucesos históricos más importantes acontecidos en la provincia en los inicios del siglo XX. Sin embargo, se conservan pocas fuentes de época que aporten datos adicionales sobre este valioso documento fílmico, hoy lamentablemente perdido. La primera mención al mismo tiene lugar en la edición del 19 de julio de 1916 de la revista porteña Excelsior, que en su sección "Crónica del Rosario", con el título de "Smart Palace", anuncia que:

Se exhibirán en este salón la $1^{\mathrm{a}}$ serie de los festejos realizados en Tucumán con motivo de las fiestas patrias celebradas en dicha provincia conmemorando el primer centenario de nuestra independencia. Esta película se exhibirá solamente en el "Smart Palace" y el espectador podrá contemplar desde aquí el aspecto que presentaba esta hermosa provincia argentina durante la celebración de las fiestas patrias. ${ }^{13}$

En el mismo número de Excelsior se informa el estreno, en el Cine Nuevo de Buenos Aires, de un film titulado Las fiestas de Tucumán y, en agosto de 1916, la publicación vuelve a anunciar la proyección de una cinta de la misma temática en el cine Select Biograph de la ciudad de Córdoba, distribuida por la Sociedad General Cinematográfica de Buenos Aires -empresa que como veremos tenía un agente activo en la ciudad de Tucumán. ${ }^{14} \mathrm{Si}$ bien ninguna de estas fuentes menciona a Del Conte como autor del film, un aviso publicado en enero de 1917, en el primer número de su revista Film Gráfico, nos provee la prueba más sólida sobre su intervención en esta cinta. Se trata de una publicidad de la "Tucumán Film", "empresa editora de la película Tucumán durante las Fiestas del Centenario, adquirida por el Superior Gobierno de la Provincia", ${ }^{15}$ que anuncia sus servicios de edición de películas cinematográficas. La compañía dice contar con talleres y galerías propias y su dirección es Las Heras 255, mismo predio del Teatro Belgrano que, como vimos, Del Conte utilizó como centro de sus operaciones comerciales. Si bien no es posible determinar, a partir de estos documentos, quién fue el operador de la cinta, está claro que el montaje fue realizado por esta efímera empresa (no vuelven a aparecer avisos sobre la misma en la revista dirigida por Del Conte) como un encargo del Gobierno de la Provincia. Luego fue probablemente distribuida a otras ciudades por el agente local de la Sociedad General Cinematográfica, que de hecho publicó en Film Gráfico una publicidad de igual tamaño y formato justo al lado de la de esta compañía editora.

\footnotetext{
13 "Smart Palace", Excelsior, n. 126, 19 de julio de 1916, p. 19.

${ }^{14}$ Véase "De Córdoba", Excelsior, n. 131, 28 de agosto de 1916.

15 "Publicidad de Tucumán Film", Film Gráfico, n. 1, 20 de enero de 1917, p. 4.
} 
Figura 1. Publicidad de la "Tucumán Film". Editora de la película Tucumán durante las Fiestas del Centenario (1916), Film Gráfico, n. 1, 20 de enero de 1917

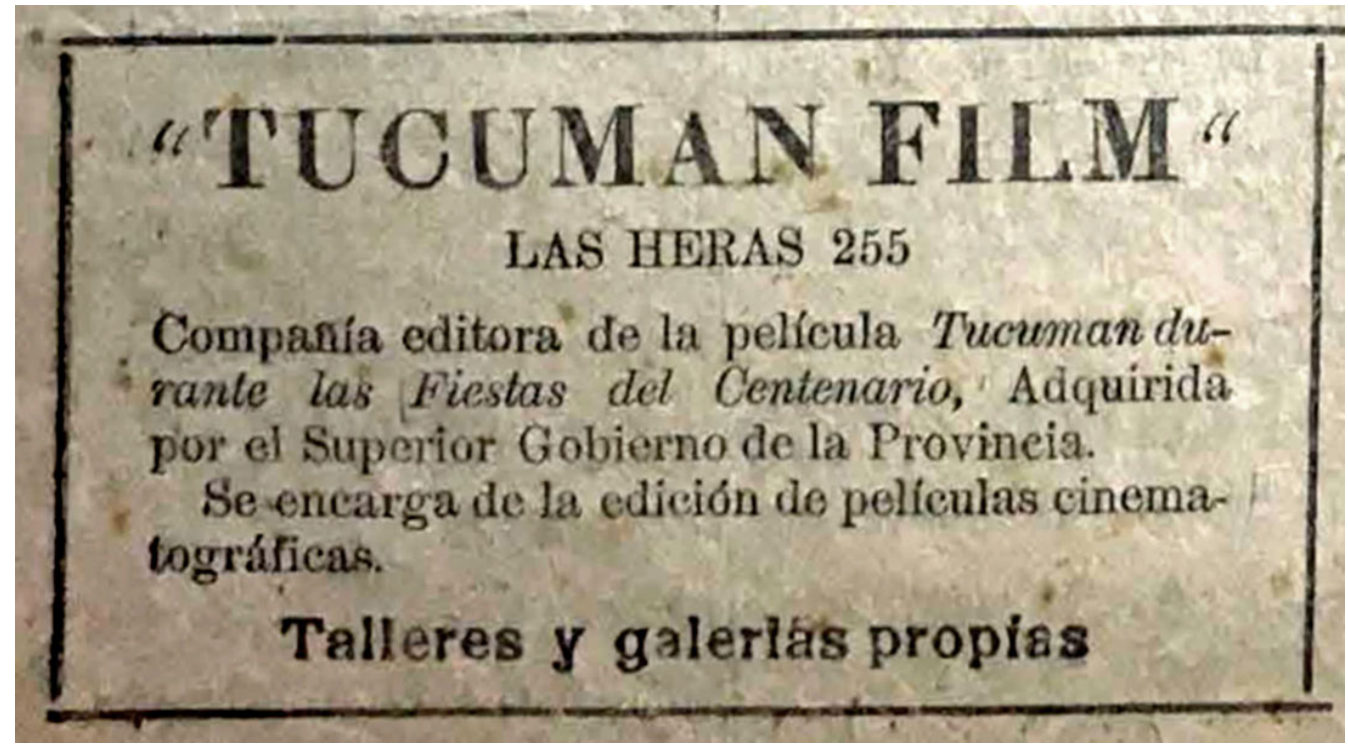

Fuente: Archivo CIFHA.

Aunque Del Conte tardaría quince años en volver a realizar un film, su segunda película, La barra de Taponazo (1932), también puede considerarse, en muchos sentidos, una obra pionera. Rodada en 1931 y producida por la empresa S.A.C.H.A. Manzanera, esta fue, en primer lugar, una de las pocas cintas realizadas en el país con el sistema Vitaphone de discos sincronizados, e incluía varios atractivos números musicales, entre ellos uno especialmente compuesto e interpretado por Julio de Caro y su orquesta. En segundo término, esta película inauguró una serie de otros films centrados en la temática del fútbol, un tópico que se volvería sumamente popular en las décadas siguientes. Por último, al situar parte de su argumento en un set cinematográfico -emplazado en los mismos estudios de la S.A.C.H.A. Manzanera, en el barrio porteño de Villa del Parque, donde se rodó-, la cinta contenía una serie de elementos metadiscursivos inusuales en el cine del período. El film estaba inspirado en un tango de Venancio Juan Clauso y Armando Tagini dedicado al futbolista Bernabé Ferreyra y, aunque hoy también se encuentra perdido, las reseñas de la época sostienen que narraba la historia de un campeón de este deporte, que abandonaba el rodaje de una película para jugar un partido mientras era perseguido por una muchacha que lo amaba y a quién él no correspondía. 
Cuarterolo y Jelicié. Hacia la conquista del Norte: el proyecto pionero de Film Gráfico y las batallas por...

Figura 2. Alejandro Del Conte dirige una escena de La barra del taponazo en los estudios de la SACHA Manzanera. En la cámara se ve al operador e iluminador Francis Boeniger y a su ayudante Raúl Ruibal. En escena aparecen las actrices Carmen Reyes y Eme Doris

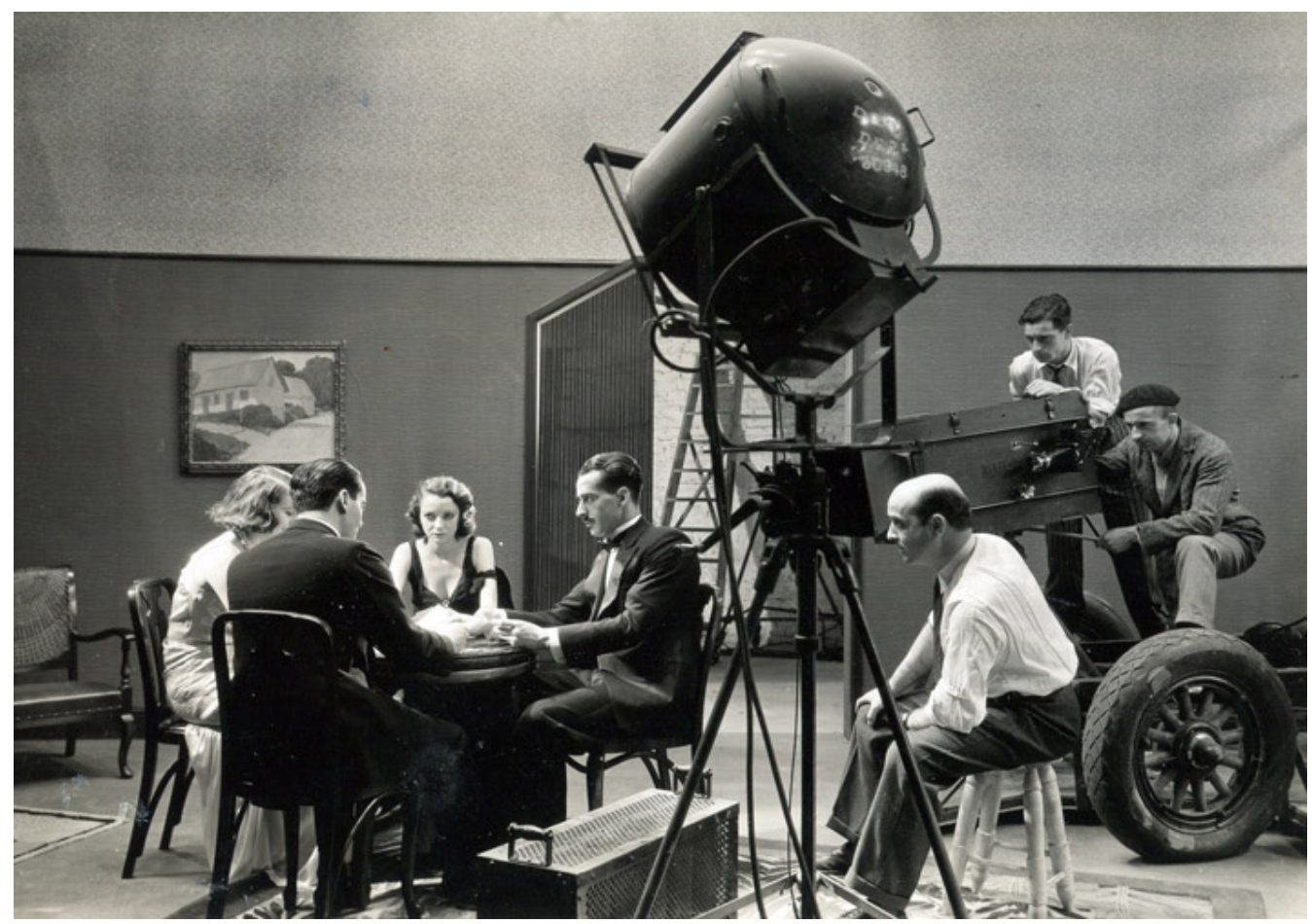

Fuente: Colección Andrea Cuarterolo.

El argumento, también a cargo de Del Conte, servía como excusa para mostrar una serie de escenas filmadas en lugares emblemáticos de la ciudad como el Hipódromo, la estación Once del Ferrocarril Oeste, el Teatro Tabarís o una cancha de fútbol. La película se estrenó más de un año después de iniciado el rodaje, el 9 de septiembre de 1932, en una época especialmente hostil para la cinematografía nacional que, desplazada por el cine sonoro norteamericano y golpeada por la crisis económica que azotaba al país, experimentaba por entonces un letargo casi absoluto. Sin embargo, a pesar de la enorme publicidad de la que gozó y de las grandes expectativas que generó, el film fue sumamente castigado por la crítica ${ }^{16}$ y resultó ser un gran fracaso de público que clausuró, en gran medida, un período breve pero intenso de experimentación con el sonido en el cine argentino. Esta fue su última incursión cinematográfica. A partir de ese momento y, quizás desalentado por la mala repercusión de un proyecto en el que había puesto todas

\footnotetext{
${ }^{16}$ Véase por ejemplo "La barra de Taponazo", El Heraldo del Cinematografista, n. 63, 14 de septiembre de 1932, p. 274; "Se estrenó la película 'La barra de Taponazo'. Un nuevo esfuerzo de la cinematografía nacional”, La Nación, 11 de septiembre de 1932; “"La barra de Taponazo' reproduce ambientes de cine y de sport", Noticias Gráficas, 10 de septiembre de 1914; "Se dio a conocer la película nacional 'La barra de Taponazo", La Prensa, 10 de septiembre de 1914.
} 
sus energías, Del Conte se volcó definitivamente al ámbito de la fotografía, que en la última década le había traído sus mayores satisfacciones.

\section{Film Gráfico, primera publicación cinematográfica del norte del país}

En un número imprescindible de la revista Cinema Action, dedicado a la historiografía de las revistas de cine en el mundo, Paranaguá (1993) sostiene que los inicios de esta prensa especializada en Latinoamérica, a principios de la década de 1910, están directamente ligados a aquellos que explotaban el negocio cinematográfico y producían periódicos corporativos y revistas profesionales o gremiales que potenciaban sus actividades comerciales. En este mismo sentido, Broitman y Samela afirman que hasta los años 50 circularon en Argentina dos modelos posibles de publicaciones sobre cine: "las que estaban dirigidas a los exhibidores o gente del medio, privilegiando las cuestiones técnicas, las estadísticas, la industria y el negocio" y "las que se dedicaban al mundo de las estrellas" (2016, p. 296), cuyo principal objetivo era promover los films de próximo estreno y los actores de moda ante un espectador/lector cada vez más conocedor y ávido de conectarse con el mundo del cine. Aunque, como veremos, Film Gráfico tiene algunos pocos elementos del segundo modelo, se trata indudablemente de una revista gremial, ubicada plenamente en la primera de las categorías propuestas. Sin embargo, si en la Capital las revistas de este tipo atendían alternadamente los tres principales aspectos de la industria, como lo son la producción, la distribución y la exhibición, en la región norte del país las actividades estaban limitadas, por este período, al campo del alquiler y la exhibición fílmica. En un artículo publicado en el décimo número de Film Gráfico a raíz de la instalación de una agencia de la North American Film Service en Tucumán —un hito que como veremos hacia el final de este artículo será clave para el desarrollo cinematográfico de la región-, Del Conte relata cómo surgió el proyecto de la revista:

Una noche, sentados en la última fila del interminablemente largo 'Majestic Palace', con cuatro plateas ocupadas de las 504 que llenan la sala, en nuestro afán de hacer algo en favor de la cinematografía en nuestro ambiente, se nos ocurrió fundar esta hoja y no descansamos hasta verla distribuida. Modestia aparte (...) a Film Gráfico se debe, sino todo, gran parte del entusiasmo con que se ha inaugurado espléndidamente la temporada. A Film Gráfico se debe la agencia de la Rosarina de Juan Lluch y, últimamente, a esta Revista los biografistas del norte deben agradecer el acontecimiento grande de que se haya instalado en esta ciudad, para atender a la zona la North American Film Service y Sudamericana". ${ }^{17}$

\footnotetext{
17 "La North American Film Service. Su programa invade la zona”, Film Gráfico, n.10, 11 de agosto de 1917, p. 1.
} 
El testimonio de Del Conte da clara cuenta de que el objetivo que guió a esta publicación, desde sus inicios, fue el de estimular el mercado cinematográfico en la región. Las pretensiones de Film Gráfico, sin embargo, nunca trascendieron lo localista. La constante inclusión de chistes y alusiones internas, de sobrenombres para referirse a las personalidades del gremio y de informaciones parciales que daban cuenta de un contexto ya sabido - rasgos también frecuentes en otras revistas gremiales del períodoes la principal prueba de que su lector modelo estaba restringido no solo a nivel profesional sino también, en este caso, a nivel regional.

Con un formato de periódico, y una extensión inicial de cuatro páginas, el primer número de Film Gráfico se publicó el 20 de enero de 1917 mediante un sistema de suscripción adelantada, con un costo de 2 pesos por semestre y 4 pesos por año. En sus páginas se definía como "la única publicación de su género en el norte" y su primer editorial daba cuenta de la pluralidad de colaboradores regionales que participaban en su realización:

Después de larga espera de tu parte y muchas aventuras y trabajos de nuestra, tenemos la incomparable satisfacción de presentarte el primer número de nuestra hoja. No profundices el estudio que ha de provocarte su lectura y lo simple de su presentación. Es modesta en verdad, pero en ella han colaborado doce personas del gremio y de las distintas provincias que abarca la zona y esto constituye no solo nuestro orgullo, sino la base de nuestro ideal. Este periódico será el aliento de los que se dedican o quieren dedicarse al cinematógrafo, el medio único de revelación mutua y el portavoz general. Es en resumen para los cinematógrafos y de los cinematógrafos. ${ }^{18}$

Los únicos miembros del comité editorial claramente identificados en la revista eran su director, Alejandro Del Conte, y su administrador, cargo ocupado alternadamente por Eduardo Grignolino y Nuño Solaesa. ${ }^{19}$ Del Conte, probablemente el único miembro del equipo con experiencia periodística previa, era quien se había puesto a cargo de la redacción, pero como "no se vive de poesías y promesas", ${ }^{20}$ delegaba la parte administrativa a un colaborador que se ocupaba de las suscripciones, de la venta y cobro de la publicidad y de la empresa de distribución

\footnotetext{
18 “Lector", Film Gráfico. Revista Semanal Cinematográfica del Norte de la República, n.1, 21 de enero de 1917, p. 1.

${ }^{19}$ El primer administrador de la revista, Eduardo Grignolino, renunció en marzo de 1917 a causa de una inminente mudanza a Buenos Aires ("El compañero Grignolino. Su renuncia", Film Gráfico, n. 6, 17 de marzo de 1917). Fue inmediatamente reemplazado por Nuño Solaesa ("Nuevo administrador", Film Gráfico, n. 6, 17 de marzo de 1917), que permaneció en el puesto hasta agosto de 1917, cuando Del Conte lo despidió por una estafa en el cobro de pagos ("Un Administrador que nos estafa", Film Gráfico, n. 10, 11 de agosto de 1917). Luego de un breve período sin encargado administrativo, Del Conte volvió a contratar a Grignolino, que finalmente había decidido permanecer en Tucumán para casarse, y este continuó en el puesto hasta el cierre de la revista al año siguiente ("Nuestro exadministrador", Film Gráfico, n. 14, 8 de septiembre de 1917).

20 "Nosotros", Film Gráfico, n. 19, 3 de octubre de 1917, p. 1.
} 
fílmica que, como vimos, funcionaba en una oficina adscripta a la revista. ¿Quiénes eran entonces esos doce colaboradores regionales a los que se refiere el primer editorial? Si bien nunca aparecen explícitamente mencionados como parte del staff de la revista, no es difícil inferir que su participación fue más bien de índole económica que intelectual. Se trata de una serie de exhibidores y distribuidores de la zona, que con sus anuncios daban apoyo a la publicación y que, ocasionalmente, se desempeñaban como corresponsales de la misma desde sus respectivas provincias. Entre los más importantes se encontraban Juan Pujol, administrador del Teatro 25 de mayo de Santiago del Estero y esporádico redactor de la revista; Pascual Di Niro, director de la Confitería-Biógrafo Paris de San Miguel de Tucumán; A. Rossi, propietario del Bar-Cine-Teatro "Casino" de Rossi \& Lico de la ciudad de Salta; Edmundo Acosta, representante en Tucumán de importantes compañías distribuidoras de Buenos Aires y Rosario; y C. Daner, gerente de la Confitería 25 de mayo de la capital de Catamarca. Si consideramos que Film gráfico tenía, como la mayoría de las revistas gremiales de la época, una clara intención orientadora del mercado, a través de la cual ponía en relieve las actividades de sus aliados o anunciantes y descalificaba o ignoraba las de sus competidores, ser colaborador de "la única publicación de su género en el norte" sin duda constituyó para estos empresarios una estrategia comercial.

Además de estos emprendedores locales, también anunciaban en Film Gráfico las grandes distribuidoras de Buenos Aires y, sobre todo, de Rosario. Estas compañías alquiladoras, como la Sociedad General Cinematográfica, la Empresa Cinematográfica Pedro Sambarino, la Cinematográfica Rosarina de Juan Lluch, la Cooperativa Biográfica, la Empresa Cinematográfica de Arsenio Vila y, especialmente, la North American Film Service y la Cinematografía Sudamericana, ambas representadas por Roberto Natalini, eran las que publicaban los avisos de mayor tamaño y frecuencia, constituyéndose en uno de los sostenes económicos más importantes de la revista. 
Cuarterolo y Jelicié. Hacia la conquista del Norte: el proyecto pionero de Film Gráfico y las batallas por...

Figura 3. Primer número de Film Gráfico, 20 de enero de 1917

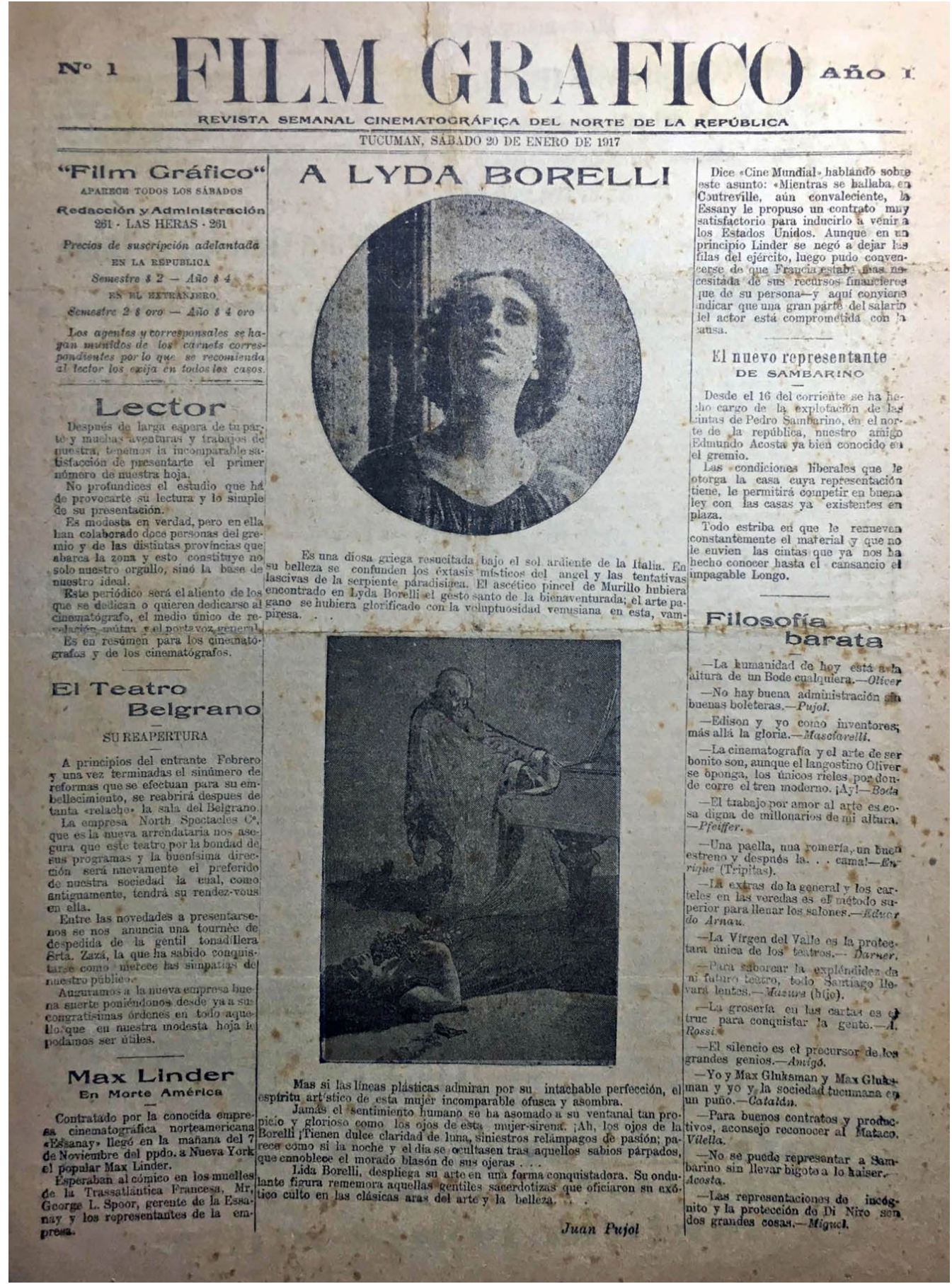

Fuente: Archivo CIFHA. 
Intentando canalizar los diferentes intereses del gremio, las notas de la revista balancearon delicadamente las informaciones internacionales y de la ciudad de Buenos Aires con las novedades regionales. En lo que respecta al cine foráneo, una de las secciones más o menos fijas - y una de las pocas firmadas - consistía en una oda o poema dedicado a una estrella de la época que se ilustraba con una fotografía o acuarela de la misma. Aunque el cine norteamericano avanzaba con fuerza en el país, en esta sección todavía se vislumbra un embelesamiento por las grandes divas del cine europeo como Lyda Borelli, Francesca Bertini o Gabrielle Robinne, solo ocasionalmente "traicionado" por la seductora Theda Bara, a quien se homenajea en dos números durante 1917. El cine europeo y norteamericano también fue objeto privilegiado de la sección "Los estrenos", en la que se publicaban largas sinopsis de las películas que triunfaban en Buenos Aires, muchas de las cuales paradójicamente nunca llegarían a la región del norte, o lo harían con meses de retraso. Una interesante excepción a la hegemonía de Europa y Estados Unidos en las noticias internacionales la constituye el décimo tercer número, que con el título "Notas de Chile" dedica dos de sus seis páginas a los pormenores de la filmación de Alma Chilena (Arturo Mario, 1917) -versión local de nuestra exitosa Nobleza Gaucha (Eduardo Martínez de la Pera, Ernesto Gunche y Humberto Cairo, 1915)- que, según el cronista a cargo de la nota, "no teme comparación con las mejores películas europeas". ${ }^{21}$

Las novedades provenientes de la ciudad de Buenos Aires también tuvieron su espacio en la revista. "Noticias Bonaerenses", "Notas metropolitanas" o "Desde Buenos Aires" fueron algunas de las secciones que se dedicaron alternadamente a cubrir las actividades de las grandes distribuidoras porteñas, los últimos estrenos de producción nacional o las vicisitudes de los exhibidores de la Capital. Sin embargo, el núcleo de esta publicación fue, sin duda, la actualidad regional, que ocupó en sus páginas un lugar privilegiado. En todos los números de Film Gráfico se incluían secciones focalizadas en las novedades cinematográficas de las principales provincias del NOA ("Desde Salta", "Desde Santiago del Estero", "Desde Catamarca", "Desde Jujuy"), cuyo propósito era difundir las actividades de los anunciantes de la revista, o bien, criticar las de sus competidores. A pesar de que Santa Fe no forma parte de esta región, la sección "Desde Rosario" estaba plenamente integrada a este segmento de informaciones del NOA, y esto se debe, como veremos, a que esta ciudad ocuparía una posición estratégica para la zona que ni siquiera Buenos Aires alcanzará en ese período. Por su parte, las secciones "Se dice" y "Por las agencias" estaban focalizadas sobre todo en la capital tucumana, sede de la propia revista, pero también núcleo del circuito cinematográfico de la región y, por tanto, asiento de la mayoría de las compañías alquiladoras de la zona.

Aunque, como mencionamos, Film Gráfico fue una revista eminentemente centrada en los pormenores comerciales de la industria cinematográfica, a partir del séptimo número comenzaron a incluirse también algunos artículos reflexivos que discurrían sobre el cine con una clara intención didáctica y legitimadora. Se trata de notas que revisaban la breve historia del medio y planteaban debates acerca de su carácter de invento moderno, de su estatuto artístico, del necesario balance entre su

\footnotetext{
21 "Notas de Chile. Cómo se ha hecho la película “Alma Chilena”, Film Gráfico, n. 13, 1 de septiembre de 1917, p. 2.
} 
Cuarterolo y Jelicié. Hacia la conquista del Norte: el proyecto pionero de Film Gráfico y las batallas por...

papel educador y espectacular, de su efecto sobre los niños o de la influencia del cine norteamericano, entre otros temas de interés. ${ }^{22} \mathrm{Si}$ bien algunas de estas contribuciones están firmadas por colaboradores, tanto de la región como de Buenos Aires, varias de ellas son anónimas o recurren a un pseudónimo bajo el cual parece ocultarse la enigmática pluma de Del Conte, que probablemente estaba haciendo sus primeras armas en el terreno de la crítica. Quizás por la corta edad de su director, la inexperiencia de sus colaboradores o lo novedoso de la empresa editorial emprendida, Film Gráfico nunca superó del todo ciertos rasgos diletantes. De hecho, uno de los principales problemas que tuvo fue el incumplimiento de la periodicidad proyectada. Aunque ya desde su título la revista se anunciaba como un semanario, solo pudo mantener esta regularidad por momentos, volviéndose costumbre que los números se espaciaran, en ocasiones por varias semanas. ${ }^{23}$ Estas inconsistencias suscitaron múltiples problemas que se vieron reflejados con frecuencia en las páginas de la revista, como la alusión a noticias que no llegaban a publicarse o luego se publicaban con notable atraso, o como las informaciones que eran anunciadas y desmentidas en el mismo número mediante la inclusión de extrañas adendas de "último momento".

El amateurismo también estaba presente en otras empresas regionales que brindaban servicios a la revista y de las que dependía su funcionamiento. En el decimocuarto número, por ejemplo, se informaba que, a causa de un problema en las máquinas de la imprenta, la revista se había visto obligada a volver a su formato original de cuatro páginas, ${ }^{24}$ en lugar de las ocho páginas que solían publicarse en ese momento. ${ }^{25}$ Asimismo, en una serie de cartas que Del Conte recibió de su administrador en 1918, éste se quejaba repetidamente por la informalidad de la imprenta, e incluso en una ocasión le comunicó que Film Gráfico no había podido publicarse por la exigencia de una deuda impaga, pero también por la falta de papel y, como si todo esto fuera poco, porque el dueño de la imprenta había caído preso. ${ }^{26}$

A pesar de estos deslices, Film Gráfico gozó del reconocimiento de sus pares y tuvo una fluida relación con otras publicaciones de cine de la época, tanto del país como del exterior. Ya en febrero de 1917 la porteña La Película anunciaba la aparición "en Tucumán de una publicación dedicada a la información cinematográfica de aquella provincia", deseándole a su colega "una larga existencia". ${ }^{27}$ En el segundo número de Film Gráfico,

\footnotetext{
22 Véase por ejemplo Pujol, J. "El cinematógrafo", Film Gráfico, n. 7, 21 de abril de 1917, p. 4; "La vida real y el biógrafo", Film Gráfico, n. 7, 21 de abril de 1917, p. 2; Señor X., "El Cinematógrafo. Proyecciones y alcance", Film Gráfico, n. 14, 8 de septiembre de 1917, p. 1; "Los niños y el cinematógrafo", Film Gráfico, n. 15,15 de septiembre de 1917, p. 1; Magnani Tedeschi, S. "El Cinematógrafo y el americanismo", Film Gráfico, n. 23, 29 de diciembre de 1917, p. 6.

${ }^{23}$ De haberse mantenido la periodicidad inicialmente estipulada, se habrían publicado 50 números durante 1917, es decir, más del doble de lo efectivamente publicado.

24 "Nuevo formato", Film Gráfico, n. 14, 8 de septiembre de 1917, p.4.

${ }^{25}$ Lo cierto es que la publicación tampoco mantuvo en este aspecto un criterio uniforme y su extensión osciló entre 4 y 10 páginas durante todo 1917.

26 "Carta de Eduardo Grignolino (Tucumán) a Alejandro Del Conte (Buenos Aires)”, 27 de mayo y 4 de junio de 1918, CIFHA.

27 "Film Gráfico", La Película, n. 19, 1 de febrero de 1917.
} 
bajo el título "Palabras de aliento", se publicaron extractos de las cartas y felicitaciones que recibió la revista en ocasión de su primer número y se reprodujeron los buenos deseos enviados por La Película. ${ }^{28}$ Con el correr de los meses, sin embargo, Del Conte comenzó a destilar una cierta animadversión contra su par porteña. En el editorial del séptimo número, titulado "Nosotros", el director alude irónicamente a otro editorial de idéntico nombre publicado en $\mathrm{La} \mathrm{Película}^{29}$ en el que los porteños se jactan de haber alcanzado un tiraje de 5.000 ejemplares, imponiéndose por sobre todas sus competidoras. Del Conte termina su escrito con un comentario burlón: "nosotros (...) tiramos -y no se crea que a la calle- 4.999, creemos representar algo de la opinión cinematográfista del norte de la República y llevamos al triunfo pisándole los talones"30. La animosidad no parece haber sido unilateral, pues Film Gráfico nunca volvió a mencionarse en las páginas de La Película a partir de entonces.

El intercambio de ejemplares, e incluso la mutua publicidad, eran costumbres frecuentes en las revistas de la época. En enero de 1918, el director de Cine Mundial —versión en español de la conocida Moving Picture World, editada entre 1916 y 1946 en Nueva York - le escribe a Del Conte una carta a través de la cual, "siguiendo la práctica [allí] establecida", ${ }^{31}$ le remite un suelto o reclame de su publicación para que adjunte a Film Gráfico, proponiéndole que el acuerdo sea recíproco. Asimismo, en septiembre de 1917 Del Conte informa haber recibido ejemplares de las revistas Cine Porteño y Excelsior de Buenos Aires, así como de la mencionada Cine Mundial y de la uruguaya $C$ inema ${ }^{32}$ Con ésta última, de hecho, se plantea una nueva disputa cuando en el decimonoveno número se la acusa de haber reproducido información de Film Gráfico sin mencionar la fuente, ${ }^{33}$ poniendo en evidencia una práctica de copias y remedos muy común en ese pequeño y endogámico circuito editorial.

A partir del vigésimo número, la revista experimentó un notorio cambio en su forma y contenido. A nivel formal, aumentó su extensión a un total de 10 páginas e incorporó una tapa sencilla en la que aparecía el título y la fecha de la publicación. En lo relativo al contenido, se modificó el título de Film Gráfico. Revista Semanal Cinematográfica del Norte de la República por el de Film gráfico. Revista semanal cinematográfica, política y de actualidades, y se incorporaron nuevos segmentos con temáticas más o menos ajenas al cine, que la transformaron en una suerte de semanario de interés general. En la editorial que introduce esta nueva etapa de la publicación, Del Conte afirma que:

En vista de la creciente aceptación de nuestra hoja, no tan solo por el gremio biografista del norte de la República, sino entre el pueblo en general hemos resuelto adscribirle una sección que versará sobre asuntos de rigurosa actualidad y de interés general, adoptando un estilo ameno y jocoso, como cuadra al

\footnotetext{
28 "Palabras de aliento", Film Gráfico, n. 2, 10 de febrero de 1917, p. 1.

29 "Nosotros", La Película, n. 28, 5 de abril de 1917, p. 1.

30 "Nosotros", Film Gráfico, n. 7, 21 de abril de 1917, p. 1.

31 "Carta del Director de Cine Mundial (Nueva York) al Director de Film Gráfico (Tucumán)", 31 de enero de 1918, CIFHA.

32 "Recibimos", Film Gráfico, n. 15, 15 de septiembre de 1917, p. 4.

33 "Cinema", Film Gráfico, n. 19, 13 de octubre de 1917, p. 2.
} 
momento actual; de excepticismos y de infundios (...)

La cuestión política, será tocada por nosotros, sin pasionismos

banderizos, como cuadra a nuestra independencia de carácter y a nuestro profundo conocimiento del ambiente. ${ }^{34}$

Teniendo en cuenta que las noticias y, sobre todo, el tono burlón e irónico con las que se las abordaba, continuaban apelando a un lector local y conocedor del medio, es difícil determinar si este giro de Film Gráfico trajo aparejado un verdadero incremento de las suscripciones. Los cambios, sin embargo, tuvieron un impacto favorable en lo que respecta al número de anunciantes. Por un lado, el aumento de páginas permitió elevar la cantidad de avisos publicados y, por otro, la ampliación temática en los contenidos de la revista posibilitó la inclusión de publicidades ajenas al ámbito del cine como las de la Cerveza Rubia y Oran, la Caja Popular de Ahorros de la Provincia, la Compañía Hidroeléctrica de Tucumán, la empresa de tramways "La Estrella del Norte" e, incluso, una sección de clasificados para profesionales de la ciudad. El último número de Film Gráfico de 1917, y también el último conservado, ${ }^{35}$ describe, en este sentido, un panorama optimista y favorable para el gremio cinematográfico en general y para la revista en particular en el año que comienza:

El 18 (...) descubre un entusiasmo extraordinario entre el gremio. Efectivamente, los cinematografistas de Tucumán que han bregado enormemente durante el año que termina, consiguiendo triunfos dignos de sus esfuerzos, se aprontan en el nuevo año para dar al arte mudo, un impulso que jamás se ha conseguido en nuestra zona.

La North American Films Service que es casi la que acapara el Norte, tiene en la persona de su agente, el Sr. Edmundo Acosta, un entusiasta invencible por el cine y a sus iniciativas debemos muchos de los progresos y adelantos dentro del ambiente, como también el haber encausado al público antes tan refractario (...) $\mathrm{Si}$ a todo esto agregamos nuestra prédica constante, que hoy trasciende al público en general dado que "Film Gráfico" es la revista popular del Norte, obtendremos que el año que comienza tiene los mejores augurios.

Apenas cinco meses después de estas animadas reflexiones, sin embargo, Del Conte había regresado a Buenos Aires dejando truncos la mayoría de sus proyectos comerciales y a la revista en manos de su administrador, Eduardo Grignolino. En los próximos apartados nos concentraremos más específicamente en los problemas y fracasos con los que se encontró Del Conte en su rol de distribuidor de cine en la región -un factor que, sin dudas, fue clave en su decisión de abandonar Tucumán-, pero aquí

34 “Film Gráfico. Su nuevo carácter", Film Gráfico, n. 20, 24 de noviembre de 1917, p. 1.

${ }^{35}$ Si bien, gracias a la correspondencia privada de Del Conte, podemos afirmar que la revista continuó publicándose por lo menos hasta mayo de 1918, no hemos podido rastrear números correspondientes a ese año. 
queremos aportar una posible hipótesis que explique el ocaso de Film Gráfico que, como mencionamos, siguió funcionando -al menos por un breve lapso sin la participación directa de su director. ${ }^{36}$ La primera pista la provee una carta que Grignolino le envía a Del Conte a Buenos Aires el 27 de mayo de 1918, en la que se lee: “Cine-Graf: no sé si habrás leído el último número de este pasquín. Yo lo busqué inútilmente para enviártelo porque esperó tu salida para atacarte. En el presente número yo le contesto pero sin mencionarle para nada. Habla de tu gestión como representante de la Biográfica". Este dato, al principio desconcertante, parecía dar cuenta de una publicación rival con un título provocativamente similar que habría surgido en la región para competir directamente con Film Gráfico. En efecto, una exhaustiva búsqueda hemerográfica permitió confirmar este hecho y aportar algunos datos adicionales. En su edición del 12 de abril de 1918, La Película anuncia que han recibido el primer número de Cine-Graf, una nueva revista "que se incorpora a nuestro gremio [y que] aparece en Tucumán" 37 y le da la bienvenida a su director, el señor G. Nuño. Contrariamente a lo que sucedió con Film Gráfico, que fue completamente ignorada por esta publicación porteña luego del anuncio de su salida en febrero de 1917, La Película continúa difundiendo esta nueva revista tucumana en sus ediciones subsiguientes. Así, en mayo de 1918 comunican la recepción del sexto número de este semanario y afirman que "trae buenos grabados y un buen meditado artículo del señor Amorós Díaz", ${ }^{38}$ y en noviembre de 1918 elogian la "buena lectura y [las] noticias interesantes sobre la marcha del negocio cinematográfico en el Norte"39 de su edición vigesimosexta. Asimismo, en julio de 1918 la revista norteamericana Cine Mundial anuncia haber recibido ejemplares de esta publicación tucumana, ${ }^{40}$ pero nunca menciona a Film Gráfico, a la que, como vimos, le había ofrecido un acuerdo de mutua difusión. Del estudio de estas fuentes podemos entonces inferir que Cine-Graf comenzó a publicarse hacía fines de marzo o principios de abril de 1918 y que continuó editándose al menos hasta noviembre de ese año (última mención que tenemos de dicha revista) cumpliendo, mucho más formalmente que su rival, la periodicidad semanal. Film Gráfico, por su parte, no parece haber sobrevivido más allá de junio de 1918. Por la correspondencia privada de Del Conte sabemos con certeza que Grignolino publicó, por su cuenta, dos números en el mes mayo ${ }^{41}$ y que tenía un tercero próximo a salir en junio de 1918, ${ }^{42}$ del que no aparecen menciones posteriores. En la última carta que se conserva de su administrador, este se queja amargamente de los problemas que tiene para cobrar a los anunciantes, que le reclaman por la falta de periodicidad de Film Gráfico y le hacen insidiosas comparaciones con Cine-Graf. Si bien es imposible determinar qué

\footnotetext{
${ }^{36}$ Las primeras cartas que Del Conte recibe en Buenos Aires desde Tucumán son del 13 de mayo de 1918, por lo que es posible suponer que partió de dicha ciudad entre fines de abril y principios de mayo de 1918 .

37 "Periodismo", La Película, n. 81, 12 de abril de 1918, p. 9.

38 "Periodismo", La Película, n. 87, 23 de mayo de 1918, p. 19.

39 "Periodismo", La Película, n. 112, 14 de noviembre de 1918, p. 18.

40 "Noticias de la pantalla", Cine Mundial, n.7, vol. 2, julio 1918, p. 407.

41 "Carta de Eduardo Grignolino (Tucumán) a Alejandro Del Conte (Buenos Aires)", 13 de julio de 1918, CIFHA.

42 "Carta de Eduardo Grignolino (Tucumán) a Alejandro Del Conte (Buenos Aires)”, 27 de mayo de 1918, CIFHA.
} 
peso tuvo esta competencia en el cierre de la revista, es indudable que dejar de ser "la única publicación de su género" en un sector tan pequeño e incipiente debió ser un duro golpe para las expectativas de Del Conte que, según se desprende de la correspondencia, regresó a Buenos Aires con el proyecto reflotar su revista en el más afianzado medio cinematográfico porteño. ${ }^{43}$

Más allá de su corta existencia, Film Gráfico fue, sin dudas, un hito fundamental en la región. No solamente contribuyó a consolidar un gremio embrionario y sumamente disperso, sino que logró mostrar el potencial comercial del NOA, captando la atención de grandes distribuidoras metropolitanas, que instalarían agencias en la zona por esos años. Hoy, sin embargo, esta publicación posee un valor adicional que es el de servir como fuente indispensable - $-\mathrm{y}$ en muchos sentidos irremplazable - para reconstruir las características de esta germinal industria cinematográfica regional, revelando las expectativas y aspiraciones de un grupo de pioneros comprometidos con el desarrollo del sector, en un momento inmediatamente previo a la entronización del monopolio hollywoodense en el país. A continuación, intentaremos reconstruir, a partir de las páginas de esta revista y de otros documentos relacionados, las principales características de la exhibición y distribución en el norte del país y los intentos de Del Conte y de sus colegas de cimentar un circuito comercial regional en esos únicos e irrepetibles años en los que, todavía, cualquier proyecto parecía posible.

\section{Algunas características de la exhibición de cine en Tucumán}

Hacia principios de 1917 la capital de Tucumán contaba con una cantidad nada despreciable de espacios de exhibición comercial. En lo que concierne a los destinados a proyectar películas, ya se habían construido dos: el Moderno y el Majestic Palace. Pero también funcionaban como cines los teatros Odeón, Politeama Argentino, Esmeralda, Alberdi y Belgrano. A ellos se sumaban los bares-biógrafo o cines-confitería, varios de los cuales fueron abastecidos por Del Conte y oficiaron, como ya vimos, de avisadores de la revista, como por ejemplo los cines-confitería París, Polo Norte y Segundo Centenario, entre varios otros. Este esquema se replicaba al interior de la provincia, aunque con una disminución drástica en la cantidad y calidad de los cinematógrafos. En la ciudad de Concepción, la segunda en importancia luego de San Miguel de Tucumán, estaban los cines Concepción, Moderno (homónimo al de la capital) y el Salón Biógrafo del Hotel Nuevo; en Tafí Viejo, el Cine Centenario; en Aguilares, el Cine "25 de mayo"; en Bella Vista, el Cine Bella Vista; etc. Las provincias aledañas repetían esa configuración centro-periferia, y a su vez tenían como centro a Tucumán. En Jujuy funcionaban el Cine Mitre, el Cine Europa y el Cinema Bar Victoria (San Salvador de Jujuy); en Salta, el Teatro Victoria, el Biógrafo Casino, el Petit Palais Mazure de la Confitería "El Águila" y el Salón Biógrafo del Hotel Salteño (Salta capital); en Catamarca, el Teatro "25 de mayo" (Catamarca capital); en Santiago del Estero, el Cine La Santiagueña, el Cine Confitería

\footnotetext{
43 "Carta de Eduardo Grignolino (Tucumán) a Alejandro Del Conte (Buenos Aires)", 4 y 13 de junio de
} 1918, CIFHA. 
"El León”, el Biógrafo de Casa Salinas (Añatuya), el Biógrafo al Café "La tripolitana" (Suncho Corral) y el Cine Renzi (La Banda).

Atendiendo a su disposición espacial y arquitectónica, los cines del norte pueden, por tanto, dividirse en dos grandes grupos: los cine-teatros y los bares-confiterías. Mientras que los primeros funcionaban con las características de la sala oscura a la italiana, con una capacidad que oscilaba entre 300 y 600 butacas; los del segundo grupo eran mucho más reducidos en su capacidad para albergar público y promovían al mismo tiempo el consumo de alimentos y bebidas, con las interferencias que esto producía en el flujo perceptivo de las películas. Esta disparidad, que se vio acentuada con el progresivo incremento de público y la construcción de espacios destinados específicamente al espectáculo cinematográfico, fue definiendo un modelo de negocio de alquiler de las cintas en el que los locales pequeños fueron quedando relegados, hasta desaparecer en la década del veinte.

Igualmente relevante resulta comprender el esquema de relaciones entabladas entre los cines y las casas alquiladoras, que estaba lejos de ser uniforme. Por un lado, estaban las salas que tenían convenios de exclusividad con las compañías alquiladoras y en las que existía una fusión de intereses entre la exhibición y la distribución. Un ejemplo emblemático es el de los cine-teatros Esmeralda (que solo exhibía cintas de la Sociedad General Cinematográfica), Moderno y Majestic (dedicados a programar cintas de la Casa Glücksmann), que a su vez replicaba a escala local la oposición entre los dos mayores actores del negocio cinematográfico en la Argentina: Julián de Ajuria y Max Glücksmann. ${ }^{44}$ Otros cines, como el Alberdi, eran el ejemplo opuesto en la medida en que exhibían material de agencias de procedencia diversa y estaban alejados de las orientaciones monopólicas de los antes mencionados. La operatoria del Alberdi para obtener películas se asemejaba en este punto a la de las pequeñas salas de bares, confiterías y cervecerías, que por lo general quedaban a merced de los agentes intermediarios que respondían a una o más compañías alquiladoras. Estos agentes a menudo ofrecían a estos cines más modestos las películas que se habían destinado a los auditorios más amplios de los cines-teatros, para que las proyectaran cuando surgía algún tiempo ocioso entre función y función, o antes de su devolución a Buenos Aires. En su calidad de viajantes, además, solían responder a los pedidos de ocasión de los administradores, asistiéndolos de urgencia por un bache de último momento en algún programa, un desperfecto técnico o cualquier otro motivo.

Se hace necesario distinguir también las funciones del administrador de las del agente. En principio, los cines contaban con un administrador que se ocupaba de la explotación del espacio. Este podía ser su dueño, un empleado a cargo, un arrendador o incluso un concesionario, ya que para la explotación de los teatros municipales se requería de la previa licitación y quien la ganaba estaba facultado también a arrendar el espacio a otra

\footnotetext{
${ }^{44}$ Para un análisis sobre la puja entre Glücksmann y de Ajuria por el control de la importación y la distribución de películas extranjeras en el país, puede consultarse Jelicié (2018). Para un análisis del mencionado antagonismo, pero desde la perspectiva de dos proyectos estético-ideológicos en conflicto, véase Cuarterolo (2019).
} 
persona, y ésta a su vez subarrendarlo a otra. La función del agente, por su parte, era la de representar a las casas alquiladoras. En algunos casos esa representación era exclusiva: la casa contrataba a una o más personas para ofrecer sus cintas a distintos cines. La Sociedad General Cinematográfica, por ejemplo, contaba con un único agente representante para la región del noroeste, de apellido Eguiguren. Este atendía la sede que dicha empresa tenía en Muñecas 248 y, lógicamente, abastecía en primer lugar al cine Esmeralda -por el convenio de exclusividad ya mencionado-, pero también a los cines de la Confitería "El León" de Santiago del Estero y "Casino" de Salta. En otros casos, los agentes se manejaban con relativa independencia de las firmas de alquiler e iban alternando según los requerimientos y posibilidades de cada cine, la época del año y la zona geográfica.

Desde luego que estos ejemplos no agotan el denso entramado de relaciones entre agentes representantes, administradores, concesionarios y propietarios de las salas del norte, a cuya complejidad hay que agregarle los cambios por la caducidad de los contratos, la entrada al mercado de nuevas casas alquiladoras o las reformas en los espacios edilicios, pero brindan al menos un panorama general del funcionamiento de los espacios de exhibición en la región.

\section{La aventura de la distribución}

“¡Ambiente biografista más prostituido que en el norte no he conocido nunca! (...) [Un] ambiente (...) pobre, excesivamente pobre, dominado por dos o tres empresas, sin importancia unas, las otras aunque de fama, poco hacían por hacernos conocer las grandes producciones que acaparaban". ${ }^{45}$ Con estas palabras de agosto de 1917, Del Conte describía cómo había encontrado el circuito exhibidor del NOA al momento de su arribo a Tucumán, un año antes. En efecto, hacia mediados de 1916 solo llegaban a la zona un puñado de empresas alquiladoras de la ciudad de Buenos Aires que, sin verdadero interés en ese mercado incipiente, cobraban precios exorbitantes por las cintas exclusivas o simplemente enviaban los saldos de su explotación metropolitana. Las dos más prestigiosas eran la Sociedad General Cinematográfica y la Casa Lepage de Max Glücksmann que, como vimos, reproducían a nivel local su rivalidad en el mercado porteño. La primera estaba representada en Tucumán por el mencionado Eguiguren, uno de los blancos preferidos de Film Gráfico, que lo bautizó con el apodo de "El inservible" y no cesó de atacarlo ni siquiera cuando fue reemplazado por el "más idóneo" Enrique Martin. La segunda tenía como agente local a Antonio Catalán, que abastecía con este programa a sus cines Moderno y Majestic.

Además, tenían presencia en la zona una serie de compañías más chicas que frecuentemente extendían su área de influencia a países limítrofes como Perú, Bolivia y Chile. Este era el caso de la Empresa Cinematográfica de Pedro Sambarino (que explotaba las películas de la compañía Cinema de Lima) y de la Compañía de Arsenio Vila (que representaba a la Empresa de Teatros y Cinemas de Perú y tenía oficinas en Buenos Aires, Lima, Valparaíso, Santiago, Iquique, Antofagasta, Concepción y Punta Arenas). Los agentes

\footnotetext{
45 "La North American Films Service. Su programa invade la zona", Film Gráfico, n. 10, 11 de agosto de
} 1917, p. 1. 
en Tucumán de estas dos alquiladoras eran Edmundo Acosta y Pascual Longo que, como vimos, eran estrechos colaboradores de Film Gráfico y amigos personales de Del Conte

La última distribuidora porteña con presencia en la región era la Cooperativa Biográfica, de la que Del Conte era agente no exclusivo. Esta era una alquiladora a la medida de las preferencias de la época: se especializaba en las cintas por episodios o "en serie", sobre todo de origen norteamericano. Si bien desde principios de la década en la Argentina este formato de cine estaba casi enteramente identificado con su vertiente francesa, con títulos como La mano de hierro, Fantomas o Los vampiros - por nombrar algunos de los más famosos de Gaumont - las opciones ofrecidas a Del Conte a lo largo de 1917 ponen en evidencia que los seriales norteamericanos ya se habían impuesto en forma contundente. ${ }^{46}$ Entre los títulos en episodios explotados por esta distribuidora en 1917 sobresalían Soborno (Graft, George Lessey y Richard Stanton, 1915), El lirio purpúreo (Under de crecent, Burton King, 1915), El naipe de los tres corazones (The Master Key, Robert Leonard, 1914), La caja negra (The Black Box, Otis Turner, 1915), Libertad o La herencia fatal (Liberty, Jacques Jaccard, Henry MacRae, 1916) y Fantomas (Fantômas, Louis Feuillade, 1913). A excepción del último, todos eran seriales producidos por la Universal Pictures, que se presentaban como policiales o thrillers con slogans de gran condensación dramática y sensacionalismo.

Estas novedades (que lo eran en términos relativos si se tiene en cuenta que en Estados Unidos se habían estrenado entre 1914 y 1915) integraban el stock de disponibilidades junto con otros films que aparecían en la lista en carácter de remanentes. Entre estos últimos incluso había varios clásicos franceses de la década anterior, como las cintas de tema bíblico La vida de Moisés (La vie de Moïse, Pathé Frères, 1905) o Vida y pasión de Jesucristo (Vie et Passion de N. S. Jésus Christ, Ferdinand Zecca, 1907), y films italianos, alemanes y franceses más recientes, pero de menor valor comercial, como Tigris (Vincenzo Dénizot, 1913), Matrimonio secreto (Matrimonio segreto, Camillo De Riso, 1913) y La lámpara de la abuela (La lampada della nonna, Luigi Maggi, 1913). La escasez de material nuevo a causa de los desequilibrios de la guerra obligaba a recurrir a los éxitos de años anteriores, cuando todavía el predominio era europeo. Las compañías argentinas se veían entonces forzadas a relanzar o, como se decía en la época, "reprisar" films, a menudo cambiándoles el título para hacerlos convivir en las carteleras con los más apetecibles films norteamericanos. A juzgar por los avisos de las revistas, esta circunstancia generó una suerte de espejismo que no dejaba ver el avance del cine norteamericano en toda su fuerza, y se podría decir que, en cierta medida, colaboró con su retraso.

Las provincias del norte, por su parte, sufrían el retraso adicional ocasionado por la distancia geográfica. Había que calcular en principio el tiempo previsto para el traslado de la cinta de un punto al otro (de Buenos Aires a Tucumán, de Tucumán a las otras provincias de la región, y a la inversa). El medio utilizado era el tren, cuyos

\footnotetext{
${ }^{46}$ Una nota de Excelsior señala esta tendencia creciente: de dieciocho series estrenadas en 1917, once son norteamericanas y siete son francesas. En: "Las cintas en series", Excelsior, n. 200, 1 de enero de 1918, p. 68.
} 
Cuarterolo y Jelicié. Hacia la conquista del Norte: el proyecto pionero de Film Gráfico y las batallas por...

recorridos variaban según el día, la empresa y el tipo de servicio brindado. ${ }^{47}$ Pero pese a ser el más rápido y eficaz de los transportes disponibles, no estaba exento de sufrir cambios de horarios y suspensiones, ya fuera por desperfectos técnicos, accidentes o incluso huelgas ferroviarias. Si la cinta era enviada para ser exhibida al día siguiente y quedaba demorada en el camino, era factible que tuviera que suspenderse la función para poder cumplir con los compromisos siguientes. Esto provocaba el tironeo entre los agentes y las empresas alquiladoras: mientras los primeros reclamaban mayor capacidad de maniobra para hacer circular las cintas (sobre todo cuando giraban por las localidades y pueblos más remotos), las segundas exigían el cumplimiento de un cronograma de explotación tan apretado y riguroso que no dejaba margen para el error. ${ }^{48}$ Este conjunto de factores no hacía más que fomentar la reticencia de la casa alquiladora a enviar las novedades tempranamente. En efecto, era preferible darle prioridad a las ciudades que entraban en el radio más cercano de la Capital para tener las cintas a mano durante su primer tramo de explotación, que era, por otra parte, el que daba mayores dividendos. Cuando bajaba el nivel de demanda, recién la compañía alquiladora se disponía a pactar fechas con sus clientes del norte. Esto ocurría en un tiempo de entre tres meses y un año desde el estreno oficial en Buenos Aires. ${ }^{49}$

Un ejemplo muy ilustrativo del conjunto de situaciones que rodeaba a las cintas distribuidas en el norte lo constituye la mencionada Soborno, ${ }^{50}$ que Del Conte solicitó por primera vez en agosto de 1917 -ocho meses después de su estreno-, pero que la Cooperativa Biográfica recién le entregó en noviembre, aduciendo que todavía era muy requerida en Buenos Aires. ${ }^{51}$ Pero el problema mayor surgió cuando la compañía le envió una contraorden: "No comprometa Soborno fechas indicadas". ${ }^{2}$ Los primeros episodios

\footnotetext{
${ }^{47}$ Las tres empresas que llegaban a San Miguel de Tucumán eran el Ferrocarril Central Norte (FCCN), también llamado "Internacional" debido a que comunicaba el norte argentino con Bolivia y Chile; el Ferrocarril Central Argentino (FCCA); y el Ferrocarril Central Córdoba (FCCCba), que requería de una combinación para conectar con Buenos Aires. Todos ofrecían servicios de carga y de pasajeros. Véase Schvarzer (2007).

${ }^{48}$ Para dar un ejemplo que se repetía a menudo: en medio de las negociaciones por la cinta en episodios Libertad, la alquiladora le exigía a Del Conte confirmar las fechas lo antes posible, sugiriéndole a tales efectos que organizara varias exhibiciones "el mismo día o cuando más al siguiente", de manera de poder maximizar el tiempo y minimizar los gastos de flete. "Carta de Manuel Brugo (Buenos Aires) a Alejandro Del Conte (Tucumán)", 12 de abril de 1918, CIFHA.

${ }^{49}$ Dato que surge del relevamiento de una veintena de estrenos del período 1916-1918, incluyendo films nacionales.

${ }^{50}$ El alquiler que debía cobrar Del Conte tenía un costo de 10 pesos por cada episodio, con un mínimo de dos episodios por envío y dos salones distintos para ser exhibidos. Otra de las condiciones era que combinara fechas inmediatas para no tener que enviar una cinta repetidas veces o evitar que giraran por adelantado. Los gastos del alquiler y del flete quedaban a cargo del exhibidor, mientras que Del Conte recibiría una comisión del total facturado del 10 por ciento, tanto por los alquileres como por la venta de los electrodos de carbón para las lámparas de los proyectores, que la empresa ofrecía en dos medidas distintas. Los afiches de propaganda, en cambio, iban sin costo, pero debían ser devueltos, y en buen estado.

51 “(Soborno) sigue alquilándose en esta ciudad y alrededores a precios convenientes: cuando empiece a aflojar tendremos el agrado de entrar en trato en esa zona". En: "Carta de Raúl Massini-Cooperativa Biográfica (Buenos Aires) a Alejandro Del Conte (Buenos Aires)", 3 de agosto de 1917, CIFHA.

52 "Carta de Manuel Brugo-Coop. Biográfica (Buenos Aires) a Alejandro Del Conte (Tucumán)", 5 de diciembre
} 
habían quedado varados en Chile por problemas de transporte y, por lo tanto, Del Conte debía rearmar el organigrama completo de envíos, con el consecuente perjuicio que esto ocasionaría a los exhibidores. Esto llevó a que uno de ellos pidiera que las cintas fueran directamente enviadas a su provincia, "pues conviene pasarla ligero a fin de que no decaiga el interés"; 53 otro exigió el uso del "tren de carga", ${ }^{44}$ alegando a su vez las molestias del calor del verano y el peligro de que se discontinuara la serie (contaba con 19 episodios); mientras que un tercero aprovechó la situación para regatear los precios de alquiler. ${ }^{55} \mathrm{La}$ situación empeoró cuando la compañía advirtió que Del Conte no estaba retornando las cintas en su debido tiempo, ${ }^{56}$ por lo que endureció las condiciones de negociación: este debía ahora comunicar a Buenos Aires las fechas de remisión, de exhibición, de días en que las cintas estuviesen paradas y de devolución en cada caso. La compañía además le negaba la exclusividad de la distribución de sus películas en el norte (ante los insistentes pedidos de Del Conte), recordándole también que tenía la facultad de colocarlas de forma directa, sin necesidad de intermediarios.

Las desavenencias continuaron por algunas semanas más. La alquiladora se mostraba decepcionada porque, a pesar de haber podido regularizar la logística, las devoluciones seguían llegando hasta veinte días más tarde de lo pactado. El gerente de la Biográfica incluso fue más lejos, al señalar que cualquier agente "devolvería el material inmediatamente, si no trabajara clandestinamente". ${ }^{57} \mathrm{La}$ acusación rozaba a Del Conte sin nombrarlo, y fuera o no el verdadero responsable, le exigía cargar con los "daños y perjuicios". Pero este se defendió con argumentos al parecer atendibles: sujeto a los manejos que le imponían algunos clientes y colegas, era él mismo el que se había visto perjudicado por el desvío de esas cintas, lo que muestra que los tironeos por la tenencia de las películas no solo se sentían en el trato entre Tucumán y Buenos Aires, sino también en el que se daba a nivel interregional. La pregunta era, entonces, qué había ocurrido entre tanto con los films, o por qué un teatro como el Alberdi postergaba sus funciones, teniendo en cuenta que los envíos habían sido despachados en tiempo y forma. Fue finalmente el santiagueño Juan Pujol, uno de los agentes más cercanos a Del Conte, el que echó luz sobre lo que había sucedido: en una carta escrita de puño y letra, aclaró que las cintas habían quedado demoradas por su responsabilidad en la localidad de La Banda, donde había pactado más exhibiciones para "ayudar" a Renzi en su "cine completamente sin importancia" ni recursos. ${ }^{58}$ No era la primera vez que algo así sucedía. En otra oportunidad Pujol demoró

de 1917, CIFHA.

53 "Carta de Juan Pujol (Santiago del Estero) a Alejandro Del Conte (Tucumán)", 14 de enero de 1918, CIFHA.

54 "Telegrama de Genovesi (Tucumán) a Alejandro Del Conte (Santiago del Estero)", 28 de enero de 1918, CIFHA.

55 "Dice que no puede pagar más. Efectivamente he tenido ocasión de ir una noche y no hace nada". En:

"Carta de Juan Pujol (Santiago del Estero) a Alejandro Del Conte (Tucumán)", 9 de enero de 1918, CIFHA.

56 "Indispensable devuelva todas las cintas detenidas indebidamente causándonos perjuicio". En: "Telegrama de Cooperativa Biográfica (Buenos Aires) a Alejandro Del Conte (Tucumán)", 7 de marzo de 1918, archivo del CIFHA.

57 “Carta de Milá Boqué-Coop. Biográfica (Buenos Aires) a Alejandro Del Conte (Tucumán)”, 25 de marzo de 1918, CIFHA.

58 "Como se sabe, el cine de La Banda es un cine sin importancia y no le es posible pagar ningún programa 
Cuarterolo y Jelicié. Hacia la conquista del Norte: el proyecto pionero de Film Gráfico y las batallas por...

unas cintas para cederlas a una "sociedad de beneficencia"; 59 pero también estaban los casos en que se debían postergar las funciones porque los rollos llegaban totalmente estropeados. ${ }^{60}$ De cualquier forma, había que pensar en una opción más de fondo para resolver ese estado de cosas. Si los problemas de la distribución del norte tenían siempre las mismas causas de origen -el centralismo de Buenos Aires, su lejanía geográfica y el consecuente menosprecio por ese mercado-, ¿por qué no cambiar de base? ¿Por qué no buscar un lugar más cercano que pudiese erigirse como principal centro abastecedor?

\section{Rosario siempre estuvo cerca}

En efecto, el estado de situación antes descrito solo comenzó a transformarse cuando se abrió la posibilidad de construir un circuito de distribución alternativo, cuyo punto de partida no estaba ya en la ciudad de Buenos Aires sino en la de Rosario, que rápidamente se estaba convirtiendo en el segundo polo cinematográfico de importancia en el país y buscaba ampliar su área de acción a nuevos mercados. Hasta agosto de 1917, la única alquiladora proveniente de esta ciudad que llegaba al NOA era la Cinematográfica Rosarina de Juan Lluch, que ante la inoperancia de sus pares porteñas, estaba cobrando velozmente fuerza en la región. Sin embargo, el hito clave en la emergencia de esta nueva logística -en la que la Film Gráfico se arrogaba haber jugado un papel fundamental-sería la llegada a Tucumán, en agosto de 1917, de manos del empresario rosarino Roberto Natalini, de dos poderosas empresas alquiladoras: la North American Films Service y la Cinematografía Sudamericana. La primera era la sucursal argentina de la North American Pictures Inc. de Nueva York, que representaba a importantes productoras estadounidenses como la World, la Metro y la Rolfe, entre otras. La Cinematografía Sudamericana era, por su parte, una de las primeras alquiladoras nacionales en haber introducido al país cintas norteamericanas y representaba a marcas como la Universal, la Blue-bird y la Butterfly, entre otras. En abril de 1917 estas dos distribuidoras se habían fusionado para constituir una única firma comandada por Natalini. La noticia quedó reflejada en el séptimo número de Film Gráfico como un acontecimiento trascendental, e iba acompañada por el anuncio de la apertura de una subsede de la compañía en Tucumán, lo que les permitiría a los biografistas del norte "apreciar lo majestuoso del material" de Natalini por primera vez. ${ }^{61}$ Si bien no hay documentos que certifiquen que se haya abierto realmente una agencia concreta, y más bien parecería que si la hubo fue con un funcionamiento itinerante, ${ }^{62}$ lo cierto es que a

por insignificante que sea su precio". En: "Carta de Juan Pujol (Santiago del Estero) a Alejandro Del Conte (Tucumán)", 3 de marzo de 1918, CIFHA.

59 "Telegrama de Juan Pujol (Santiago del Estero) a Alejandro Del Conte (Tucumán)”, 20 de enero de 1918, CIFHA.

60 "Mucho lamento el percance sufrido con su cinta Fantomas [pero] sin duda la cinta la han pasado infinidad de máquinas hechas cafeteras". En: "Carta de Juan Pujol (Santiago del Estero) a Alejandro Del Conte (Tucumán)", 8 de abril de 1918, CIFHA.

${ }_{61}$ "La Sudamericana y la North American Films Service", Film Gráfico, n. 7, 21 de abril de 1917, p. 1.

${ }^{62}$ Film Gráfico habla de la calle Muñecas 248, que es la misma dirección de la subsede de la Sociedad General Cinematográfica. A partir de septiembre Acosta publica la dirección de Las Heras 465, que también es la de Pascual Longo. 
partir del 15 de junio la empresa fusionada inauguraría un servicio con la capacidad de "proporcionar a la plaza hasta cien partes de estrenos diarios, partes que bastan para dar películas distintas a dos cines competidores, sin que uno pase las cintas que ha estrenado el otro". ${ }^{63}$ Como último anuncio de relevancia, se informaba que los agentes nombrados por Natalini harían base en San Miguel de Tucumán, pero con potestad de representar a la provincia entera, así como a Salta y Santiago del Estero.

Figura 4. Publicidad de la North American Film Service, representada por el rosarino Roberto Natalini, Film Gráfico, n. 12, 25 de agosto de 1917

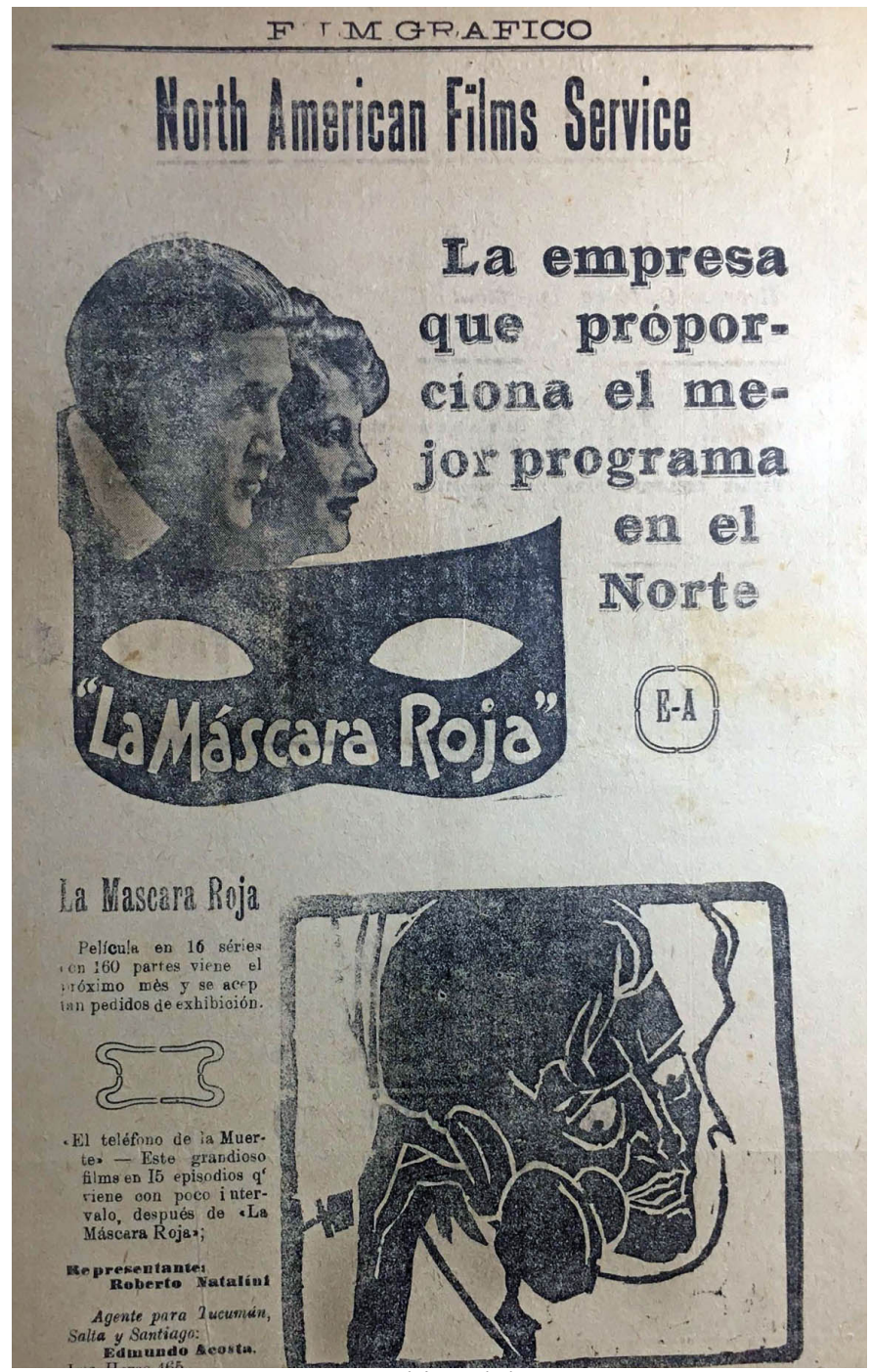

Fuente: Archivo del CIFHA.

63 "Un verdadero acontecimiento. La North American Film Service entre nosotros", Film Gráfico, n. 9, 2 de junio de 1917, p. 1. 
Dicho y hecho: el surtido diario de películas se dio como estaba anunciado, y ya en agosto Film Gráfico no dudó en calificar el resultado obtenido como un triunfo indiscutible. ${ }^{64} \mathrm{Si}$ bien la mayor parte de las novedades no llegarían sino hasta principios de septiembre, una de ellas, El misterio de la mancha roja (The Crimson Stain Mistery, T. Hayes Hunter, 1916), ya estaba proyectándose con "éxito loco" en las principales salas de Tucumán y alrededores. Luego será el turno de La máscara roja (The Purple Mask, Grace Cunard y Francis Ford, 1916), El teléfono de la muerte (The Voice On the Wire, Stuart Paton, 1917), El romance de Gloria (Gloria's Romance, Walter Edwin y Campbell Gollan, 1916) y La intriga rusa (Darkest Russia, Travers Vale, 1917). El diagnóstico indicaba que la agencia de Natalini estaba encabezando los programas de los exhibidores de las capitales de Tucumán, Santiago del Estero y Salta, así como de los cines de "la mayoría de los pueblos de la campaña" (Añatuya, Concepción, Tafí Viejo, San Pedro de Jujuy, Bella Vista, Embarcación) ${ }^{65}$ En el balance de la nota varios motivos justificaban el logro obtenido. Entre ellos estaba el entusiasmo con que la revista había encarado la temporada, dándole la primera plana a las compañías de cine rosarinas, sobre todo a la North American Films Service, "acontecimiento grande" que "los biografistas del norte deben agradecer". ${ }^{66}$

Pero no menos relevante era el papel que estaban jugando los agentes cinematográficos, que movían cielo y tierra para que no quedara cine en la región que no incluyera al menos una película de Natalini en sus programas, lo que implicaba un trabajo de ida y vuelta que debía procurar también que el abastecimiento desde Rosario fuera fluido y permanente. De hecho, a fines de agosto un retraso en la partida de novedades, causada inicialmente por una nueva huelga ferroviaria ${ }^{67}$ motivó que los agentes representantes decidieran viajar a Rosario a reunirse con Natalini para ajustar algunos detalles relativos a la logística, en lo que Film Gráfico denominó "una promenade de trascendencia". ${ }^{68}$ La urgencia se debía a que varias salas ya habían anunciado los títulos en sus carteleras. Estos exhibidores eran nuevos clientes para la North American, lo que sin dudas agregaba una presión extra a los agentes intermediarios. Con el correr de los meses, estos incluso lograrán que varios exhibidores dejen a sus abastecedores históricos para ser reemplazados por los de Natalini. Ese será el caso, por ejemplo, de los administradores Rossi y Lico del "Casino" de Salta, quienes después de varios años de convenio comunicarán su decisión de prescindir de la Sociedad General Cinematográfica, en parte por la ineficacia de sus representantes provinciales ("El inservible Eguiguren"), y en parte por "lo flojo" de los programas enviados desde Buenos Aires (vinculados, según Film Gráfico, con "el fracaso de la Paramount"). ${ }^{69}$ Lo

64 "La North American Films Service. Su programa invade la zona”, Film Gráfico, n. 10, 11 de agosto de 1917, p. 1.

${ }^{65}$ La North American Films Service. Su programa invade la zona", Film Gráfico, n. 10, 11 de agosto de 1917, p. 2.

${ }^{66}$ La North American Films Service. Su programa invade la zona”, Film Gráfico, n. 10, 11 de agosto de 1917, p. 1.

${ }^{67}$ Véase "La huelga ferroviaria y las remesas de cintas", Film Gráfico, n. 11, 18 de agosto de 1917, p. 1.

68 "Viaje de Acosta y Di Niro a Rosario", Film Gráfico, n. 12, 25 de agosto de 1917, p. 2.

69 "La vuelta al redil", Film Gráfico n. 23, 29 de diciembre de 1917, p. 5. 
cierto es que no era el momento de desperdiciar las conquistas alcanzadas, que estaban fundadas en gran medida en el desplazamiento de unas fuerzas históricas por otras más nuevas. La "promenade" a Rosario, en ese sentido, podía considerarse también como una ratificación de ese gran objetivo que era "dar mayor impulso a la agencia y desterrar toda la competencia posible". ${ }^{70}$ Palabras más, palabras menos, ese era el modo en que se expresaba también uno de los agentes que se había reunido con Natalini: "Tendremos materiales para combatir a todos". ${ }^{71}$

En lo que respecta a Del Conte, si bien su vínculo con la Cooperativa Biográfica seguía vigente, sus conflictos con esta compañía y su negativa a otorgarle la exclusividad fueron como un permiso para ir a tocar otras puertas y explorar, eventualmente, nuevos caminos. En sus intentos por ampliar los horizontes comerciales hubo comunicaciones con varias compañías, pero fueron las que mantuvo con Natalini las que sin dudas despertaron más su inquietud. En rigor de verdad, no se trataba de un vínculo nuevo si se considera que las compañías representadas por Natalini estaban entre las principales avisadoras de Film Gráfico y eran objeto de atención permanente de las notas publicadas por la revista. Pues bien, la correspondencia de Alejandro Del Conte muestra además que, hacia mediados de abril de 1918, la relación con Natalini prometía afianzarse, a instancias de una visita que este planeaba realizar a Tucumán de manera inminente para tratar varios asuntos en la zona. La noticia se la comunicaba Alfredo Maubrigades -socio de Natalini y futuro propietario de los cines Majestic, Esmeralda y Social de San Miguel de Tucumán en la década del veinte-, en respuesta a una carta que Del Conte le había enviado un par de semanas antes. Entre esos asuntos, sin dudas el que más sobresalía era "el propósito de establecer un gran cine" 72 en el centro de la ciudad, para lo cual Del Conte era llamado a colaborar en la búsqueda de un terreno libre. Era el momento en que Natalini se había consolidado en el negocio de la exhibición más allá de Rosario, al adquirir en propiedad los cines Newbery y Colón de Córdoba, donde además abastecía como distribuidora a seis de las ocho salas de la ciudad. Esto propiciaría la colocación definitiva de las "selectas cintas americanas" que aparecían con frecuencia en los avisos de Film Gráfico. La carta agregaba que "el señor Natalini era hombre de acción, y que difícilmente se resignaría a retirarse de la plaza de Tucumán sin antes quemar sus últimos cartuchos (y créame que hay pólvora para rato)". ${ }^{73}$

Estas noticias resultaban inmejorables para un agente ávido de novedades como Del Conte, quien ya había mostrado interés por la North American Film Service en un temprano artículo de marzo de 1917, el cual revelaba el precio que había que pagar por la representación de esta compañía en el norte. Si bien la cifra era "fabulosa" para una zona donde todos "pagan la mitad", eso "se explica si se tiene en cuenta lo

\footnotetext{
70 “La vuelta al redil”, Film Gráfico n. 23, 29 de diciembre de 1917, p. 2.

${ }^{71}$ Acosta, Edmundo, "A última hora”, Film Gráfico n. 12, 25 de agosto de 1917, p. 4.

72 "Carta de Alfredo Maubrigades-North American Films Service (Córdoba) a Alejandro Del Conte (Tucumán), 12 de abril de 1918, CIFHA.

73 "Carta de Alfredo Maubrigades-North American Films Service (Córdoba) a Alejandro Del Conte (Tucumán), 12 de abril de 1918, CIFHA.
} 
'fabuloso' del material de esta casa". ${ }^{74}$ Ese material era de interés porque precisamente estaba compuesto por la misma clase de películas que Del Conte pedía a la Cooperativa Biográfica, esto es, los seriales de origen norteamericano, que como ya vimos estaban experimentado un boom en 1917. En el artículo de Excelsior titulado "Las cintas en series", se pone claramente en evidencia la participación que tuvieron las alquiladoras argentinas en dicho proceso de recambio:

Estas películas han sido estrenadas por las casas alquiladoras en la siguiente forma: Max Glücksmann: siete (El secreto del bosque, El misterio de la doble cruz, Patria, La Amenaza oculta, El secreto del submarino, Ravengar, La mujer desdeñada). North American Films Service: cinco (El romance de Gloria, El teléfono de la muerte, Los peligros del servicio secreto, La máscara roja, El misterio de la mancha roja); Cinematográfica Sud-Americana: tres (La hija del circo, Libertad, El fantasma gris); Cinematográfica Rosarina: dos (Ultus, Los misterios de Myra); Cooperativa Biográfica: una (Soborno). ${ }^{75}$

La lista está encabezada por la Casa Glücksmann, aunque el dato pasa de inmediato a segundo plano si se observa que las tres compañías que le siguen tienen asiento no en Buenos Aires sino en Rosario: North American Films Service, Cinematográfica Sud-Americana, Cinematográfica Rosarina. Estas acaparaban casi el 60 por ciento de las películas en serie importadas en 1917 en el país, lo cual constituía, en números enteros, diez para Rosario y ocho para Buenos Aires. Desde la perspectiva de las provincias del norte, no había mejor noticia que verificar ese desplazamiento que volvía a Rosario un centro de distribución más cercano y relevante que Buenos Aires, al menos en lo referente a ese segmento particular de películas.

\section{Boicot a las confiterías}

Por su parte, la Cinematográfica Rosarina, que a partir de la fusión de las otras dos pasaría al segundo lugar en importancia, también estaba contribuyendo a dinamizar el circuito norteño. En el mes de abril se había anunciado que Edmundo Acosta, ${ }^{76}$ representante hasta ese momento de Pedro Sambarino -otro distribuidor rosarino que, como vimos, estaba muy vinculado al norte por su injerencia en el mercado de Bolivia y Perú-, iba a tomar las riendas de la sede que Juan Lluch tenía en Tucumán, acaparando con programas nuevos, "menos dos, todas las confiterías". ${ }^{77}$ Las novedades en cuestión pertenecían a la productora catalana Royal Film (ex Hispano Films), de la cual Lluch era el importador exclusivo en la Argentina. Entre los títulos de esta productora estaban Los muertos hablan (Alberto Marro, 1915), La tierra de los naranjos (Alberto Marro,

\footnotetext{
74 “Seis mil pesos", Film Gráfico, n. 6, 17 de marzo de 1917, p. 2.

75 "Las cintas en series", Excelsior, n. 200, 1 de enero de 1918, p. 68.

${ }^{76}$ Acosta a su vez renunciará en junio a la Compañía Rosarina para pasar, junto a Miguel Di Niro, a las filas de Natalini. El lugar vacante en la agencia de Lluch será ocupado por José Oliver.

77 "La Cinematográfica Rosarina”, Film Gráfico, n. 7, 21 de abril de 1917, p. 2.
} 
1914) -sobre una novela de Blasco Ibáñez-, Barcelona y sus misterios (Alberto Marro, 1915) y el más promocionado del año, Juan José (Ricardo de Baños, 1917), que al contar con una sola copia tuvo que hacer un periplo de varios meses por las provincias, empezando "por el 25 de mayo de Santiago del Estero para pasar luego a Jujuy, Salta, Tucumán y algunos pueblos de campaña...". ${ }^{78}$ Recordemos que este escenario era posible porque España se había establecido como un centro de producción y comercio internacional, dado su carácter de país neutral en la guerra. Esto permitió sustituir en determinada medida la escasez de films de otros países europeos, lo que tampoco significa que no llegara ninguno, como lo muestra la propia Cinematográfica Rosarina al introducir también una comedia dramática como Las cadenas (Un mariage de raison, Louis Feuillade y Léonce Perret, 1916) o incluso Los vampiros (Les vampires, Louis Feuillade, 1915), para nombrar dos de los títulos franceses más promocionados en Tucumán durante ese año.

Figura 5. Aviso publicitario de la Empresa Cinematográfica Rosarina de Juan Lluch, Film Gráfico, n. 9, 2 de junio de 1917

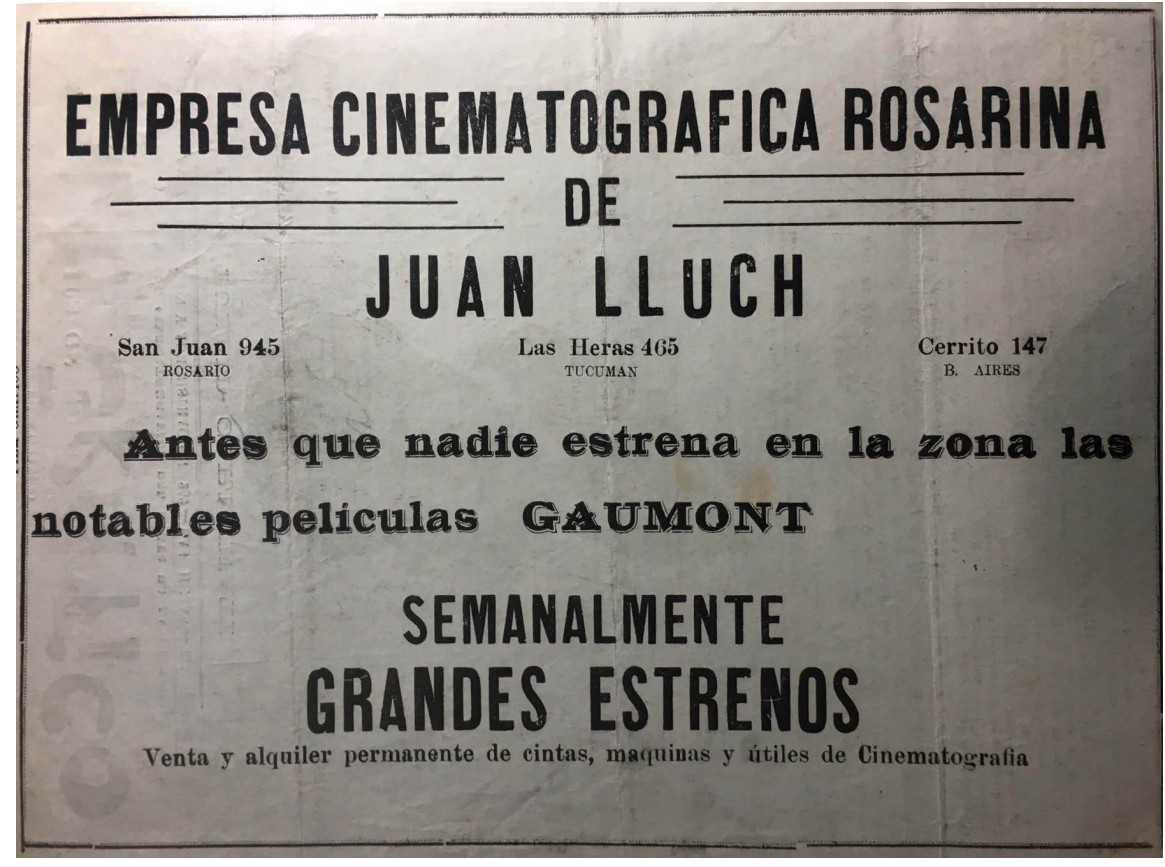

Fuente: Archivo CIFHA.

Pero no debe pasar inadvertido el hecho de que a la Cinematográfica Rosarina solo le faltaran un par de confiterías para "acaparar" por completo el circuito de la capital tucumana. En principio, esto muestra la avidez que tenían las agencias rosarinas por ese segmento de la exhibición al parecer más pequeño, pero no menos redituable, al punto de

78 “Juan José”, Film Gráfico, n. 15, 15 de septiembre de 1917, p. 1. 
Cuarterolo y Jelicié. Hacia la conquista del Norte: el proyecto pionero de Film Gráfico y las batallas por...

que algunos lo veían como la principal competencia de los cine-teatros. ${ }^{79}$ A juzgar por las reacciones de los administradores de estos últimos, esa visión parecía bastante certera. En efecto, uno de ellos -y nada menos que Juan Orti, exsocio de Del Conte en el Belgranodecidió abrir una denuncia por irregularidades que fue elevada a la Municipalidad. Según Orti, así como otros administradores que se fueron sumando a la iniciativa, las confiterías no cumplían con las condiciones establecidas para la ejecución de espectáculos, pues apenas se habían habilitado para servir comidas y bebidas. Mientras tanto, los administradores de cine-teatros eran los únicos que cargaban con los costos de cumplir con esas normas, sufriendo según ellos la deslealtad comercial. La denuncia se amparaba en la llamada "Ley Avellaneda", ${ }^{80}$ que imponía condiciones como "fijar al suelo mesas y sillas, colocar mangas de incendio, pasillos de a un metro cada cien asientos, etc.", ${ }^{81}$ esto es, una "lista de absurdos" que según Film Gráfico tenía como único fin proteger al cine regenteado por Orti. Pero el ataque no se limitó a los cines-confitería sino que también se dirigió a las agencias y representantes "en plaza", a los que, por intermedio de la Dirección de Rentas, se les exigía el pago de una patente de explotación de 600 pesos anuales, "que es lo mismo que ellos se eclipsaran". ${ }^{82}$ La pregunta era con qué clientes subsistirían las agencias (ante la inminencia de la clausura de las confiterías) y con qué dinero, por tanto, habrían de pagar dicho canon. ${ }^{83}$ Era evidente que la operación se dirigía a una clase de agentes comerciales que, como Del Conte, dependían de ese tipo de locales, y viceversa.

La batalla llegó a tener enfrentamientos cuerpo a cuerpo, como cuando Orti acusó a Del Conte de llevar adelante una "agencia clandestina", lo que derivó en la publicación por parte de este último de un certificado firmado por el presidente del Consejo Deliberante mostrando que la denuncia era falsa. ${ }^{84}$ Era claro que Del Conte usaba la revista como una herramienta para defenderse, amplificando los aspectos que lo beneficiaban y que al mismo tiempo ponían en ridículo al adversario. Otra de sus ácidas y humorísticas intervenciones tuvo lugar en el que posiblemente fuera el momento culmine de la pelea, cuando el "gremio biografista" fue a reclamar ante las puertas de la Intendencia Municipal que las confiterías debían clausurarse. El demoledor reporte de Film Gráfico, por supuesto a favor de los "cines con confitería", no por risueño dejó de decir lo que importaba: que el "Intendente Maciel, que es persona sensata, no les llevó el apunte". ${ }^{85}$ La declaración tuvo carácter de noticia puesto que a partir de allí los ánimos empezaron a calmarse, y de hecho Del Conte pudo ver con alivio que Orti retiró las denuncias pocos días más tarde. Si el año 1918 tenía desafíos por delante, al menos había obstáculos que parecían poder superarse.

\footnotetext{
79 "Los salones comprendiendo lo grande del esfuerzo que deben realizar para traer el público que les quita las confiterías perfeccionan sus programas diarios...". En: "La temporada", Film Gráfico, íbid., p. 2.

${ }^{80}$ En referencia a la también llamada "Ley de Inmigración y Colonización" ( $\left.N^{\mathrm{o}} 817\right)$, aunque lo más probable es que los términos legales a los que se referían provinieran de una norma de jurisdicción municipal o provincial.

81 "El problema de las confiterías", Film Gráfico n. 15, 15 de septiembre de 1917, p. 1.

82 "Resultado de las denuncias de Orti", Film Gráfico n. 14, 8 de septiembre de 1917, p. 2.

83 "Resultado de las denuncias de Orti", Film Gráfico n. 14, 8 de septiembre de 1917, p. 2.

84 "Las patas de la sota", Film Gráfico n. 13, $1^{\circ}$ de septiembre de 1917, p. 2.

85 "Confiterías con cine y el gremio biografista", Film Gráfico n. 20, 24 de noviembre de 1917, p. 5.
} 


\section{Los emisarios de Natalini}

Desde su llegada a Tucumán, en 1916, y hasta abril de 1918, que es el momento en que se esperaba la visita de Natalini, Del Conte había pasado por las más variadas instancias en pos de intervenir activa y favorablemente sobre el circuito cinematográfico norteño, y a pesar de los obstáculos encontrados en el camino, tanto trabajo parecía estar dando sus frutos. En efecto, a principios de 1918 había sobradas muestras de su contribución a un logro sin precedentes: 1917 había terminado con una transformación notable del mapa de distribución norteño. Esto no solo se observaba en el arribo de las compañías rosarinas - con Natalini a la cabeza- y su firme convicción de obtener allí una posición dominante, sino también en la reactivación que esto llevaba al quehacer cinematográfico en su conjunto. El balance y proyección que hace Film Gráfico en su último número del año lo describe con elocuencia: "La North American Films Service [en diciembre de 1917] es casi la que acapara el Norte" y, por medio del esforzado trabajo de sus representantes, la artífice de "muchos de los progresos y adelantos dentro del ambiente, como también de haber encausado al público". ${ }^{86}$

Ante semejante diagnóstico, las expectativas depositadas en la temporada que se avecinaba no podían ser menos que alentadoras, más aún si la cabeza del nuevo pool en ascenso había "encontrado la mejor voluntad y simpatía" para con Del Conte. Al menos eso es lo que había manifestado Alfredo Maubrigades en la carta del 12 de abril, cuando le comunicó a Del Conte el interés de Natalini por construir un cine en Tucumán. Pero esa no fue la única carta. Otra carta enviada desde Rosario el día 13 informaba a Del Conte que la empresa había recibido su petición y, "en el caso de que se establezca una sucursal en Tucumán, me será muy grato recomendarlo [por Del Conte] a Natalini" ${ }^{87}$ La información es valiosa porque, en principio, confirma que la compañía rosarina todavía no había establecido una subsede en Tucumán, pese a que prestaba servicios desde junio de 1917 y contaba con representantes de mucha llegada en la zona. En segundo término, porque transparenta el denodado esfuerzo de Del Conte para que alguien de la compañía de Natalini tomara nota de sus requerimientos. Como se ve, estos no se limitaban al típico recordatorio por los pagos adeudados de los avisos, sino que mostraban una ambición de "cobro" mayor: que la eventual agencia tucumana le fuera otorgada a él. A fin de cuentas, era natural que alguien de la zona que había participado tan activamente del crecimiento de la empresa, quisiera ocupar un lugar en ella. Los favores que le solicitaba Natalini para encontrar un lugar para su cine no hacían más que darle pertinencia a ese pedido. Precisamente, fue sobre ese favor que versó la última carta de la North American Film Service a Del Conte. De ella se desprende que este había ofrecido el teatro Belgrano como una alternativa al pedido de Natalini, quien por intermedio de Maubrigades contestó:

Agradezco su última atenta, especialmente en lo referente a su aviso de tener a su disposición el Teatro Belgrano, lamentando que precisamente sea ese local el que menos

\footnotetext{
86 “Un año más”, Film Gráfico, n. 23, 29 de diciembre de 1917, p. 4.

87 "Carta de la Compañía de Roberto Natalini (Rosario) a Alejandro Del Conte (Tucumán)”, 13 de abril de 1918, CIFHA.
} 
agrada al señor Natalini para el objeto que persigue al querer instalar un cine en esa. Su deseo sería poder conseguir un local en la misma plaza o sitio aparente para poder levantar en él un gran edificio, para lo cual se podría hacer alguna combinación con el propietario, combinación que resultaría beneficiosa para ambos. Si fuera posible esto le estimaría me lo comunicara en su oportunidad y a esta, para enterar al señor Natalini, quien se encuentra momentáneamente en Buenos Aires. ${ }^{88}$

¿Cómo es posible que Del Conte ofreciera el avejentado teatro en el que había intentado hacer sus primeras armas y por el que tanto había renegado durante 1917? Es oportuno aclarar que, por esas fechas, la posesión del Teatro Belgrano había quedado vacante debido a un litigio que su concesionario mantenía con la Municipalidad, lo que en cierta medida vuelve verosímil la propuesta de Del Conte. ${ }^{89}$ Pero, no obstante, la pregunta apunta más bien a otra cosa: ¿qué posibilidades había de hacerle creer a uno de los empresarios más importantes del país en pleno proceso de expansión que esa idea fuera sensata y atendible? Natalini, que en los membretes de la North American figuraba como "representante en Rosario y en todas las provincias del Norte de la República", en 1918 ya está en vías de ser mucho más: en octubre abriría la sede comercial de Natalini y Cía. en Buenos Aires ${ }^{90}$ para anunciar los films del famoso "contrato del millón de dólares" de Chaplin, a los que luego se van a sumar los "programas selectos" de Blue Bird, Metro, Butterfly y World. En paralelo, Natalini va a tomar la representación de otra compañía internacional fundada en febrero de 1919 con bombos y platillos, el Sindicato Cinematográfico Sudamericano, que le ofrecerá gestionar dos sedes: una en la provincia argentina de Tucumán y la otra en "una casa de tres pisos" ${ }^{91}$ en Río de Janeiro. También se aprestaba a compartir el control del mercado uruguayo junto al austríaco Max Glücksmann, con el que haría importantes convenios durante los años veinte (así como con Julián de Ajuria), lo que ya resulta suficiente como para tener una dimensión de quién era el hombre que había rechazado el ofrecimiento de Del Conte.

\section{Último tren: Tucumán-Buenos Aires}

Pese al traspié del Belgrano, seguía pendiente el "favor" de la intermediación inmobiliaria y, sobre todo, la esperada visita de Natalini, aunque desafortunadamente no se conservan más cartas de North American Film Service como para saber cómo siguió el asunto. Los pocos rastros documentales que existen, más bien, indican que ese

\footnotetext{
88 “Carta de Alfredo Maubrigades (Rosario) a Alejandro Del Conte (Tucumán)”, 22 de abril de 1918, CIFHA.

${ }^{89}$ La correspondencia muestra que aun en Buenos Aires Del Conte seguía esos episodios de cerca y no perdía la esperanza de volver a administrar el teatro alguna vez: "Respecto del asunto del Teatro mañana viernes se resuelve definitivamente a favor o en contra", "Carta de Miguel Lustozzi (Tucumán) a A. Del Conte (Buenos Aires)", 16 de mayo de 1918, CIFHA.

90 "Natalini y Cía. Instalación de sus tareas", Excelsior, n. 234, 4 de septiembre de 1918, p. 7.

${ }^{91}$ Natalini, Roberto, "Campo neutral", Cinema Star, n. 147, 22 de junio de 1921, p. 4.
} 
encuentro nunca pudo concretarse. Nada hacía pensar, por otra parte, que a principios de mayo Del Conte dejaría Tucumán, y lo cierto es que si hay otras alusiones a Natalini en la correspondencia, estas son del momento en que Del Conte ya estaba en Buenos Aires. La última data del 13 de junio, un mes después de su regreso. Se trata de una carta de Eduardo Grignolino que revela que la visita de Natalini era inminente en junio:

Espero me informaras si a tu vez ya cobraste las cuentas de Cooperativa y de Natalini. A propósito de Natalini he sabido por intermedio de Maubrigades que este señor será en Tucumán entre algunos días y esta noticia en vez de alegrarme me puso de humor negro porque, a causa de la informalidad de Baclini, el suelto que se refería a Natalini no salió en el periódico mientras habría podido ser de verdadera actualidad. ${ }^{92}$

El affaire con el imprentero parecía un cuento de nunca acabar, y estaba echando a perder los últimos recursos que quedaban para llamar la atención de Natalini en su mentada visita. Si bien no aporta información precisa sobre la intención con la que se había escrito ese artículo, la cita muestra que a mediados de junio la sociedad Del Conte (desde Buenos Aires) - Grignolino (desde Tucumán) todavía tenía que cobrar algunas cuentas de Natalini, así como de la Cooperativa Biográfica. Estaba por salir el último número de Film Gráfico del que se tiene conocimiento y Grignolino sumaba otra mala noticia a las varias que, en las últimas semanas, le había enviado a Del Conte, como el surgimiento de una competidora tucumana como Cine-Graf, los problemas financieros que atrasaban la publicación de la revista o incluso la presunción de que la vinculación con Natalini a través de sus agentes representantes amigos no estaba teniendo los resultados esperados. ${ }^{93}$ Complementariamente a lo ya dicho, la sospecha de que Del Conte había viajado a Buenos Aires por una enfermedad contraída de forma intempestiva es una hipótesis plausible, que se articula con un hecho asombrosamente vigente en 2021: varias de las cartas que recibe a su vuelta hacen alusión a una "peste"94 que azotaba la zona norteña y que se anticiparía a lo que iba a ser la llamada "Gripe Española”, que afectó con fuerza a la zona centro y norte del país al año siguiente. Es lógico pensar que, para entonces, ya no había opción ni tampoco deseo de volver a Tucumán por parte de Del Conte.

Con estas certezas y misterios se cerraba entonces un capítulo por demás relevante de la historia del pionerismo cinematográfico en el norte argentino, en donde Alejandro Del Conte tuvo una intervención destacada. Su compromiso en el desarrollo de ese circuito puso en evidencia el gran potencial cultural y comercial de la región, en un momento

92 "Carta de Eduardo Grignolino (Tucumán) a Alejandro Del Conte (Buenos Aires)”, 13 de junio de 1918, CIFHA.

93 "La combinación Acosta-Miguel-Pujol todavía es un mito". En: “Carta de Eduardo Grignolino (Tucumán) a Alejandro Del Conte (Buenos Aires)", 13 de mayo de 1918, CIFHA.

94 "Espero que hayas hecho un feliz viaje y no haya tomado posesión de ti la nostalgia del Jardín de la República con su intervención interminable, su miseria, sus bichos y la peste bubónica-neumática". En: "Carta de Eduardo Grignolino (Tucumán) a Alejandro Del Conte (Buenos Aires)”, 13 de mayo de 1918, CIFHA; "Aquí produciéndose con menos fuerza la terrible neumonía pestosa". En: "Carta de Miguel Lustozzi (Tucumán) a Alejandro Del Conte (Buenos Aires)", 16 de mayo de 1918, CIFHA. Además, al menos tres de los socios de Del Conte en Tucumán le preguntan por su estado de salud a su regreso a Buenos Aires. 
en el que la mayor parte de los empresarios del cine no habían demostrado verdadero interés por ella. A tales efectos, su revista Film Gráfico sirvió como caja de resonancia de un ambicioso proyecto de impulso al sector cinematográfico norteño, estableciendo como base no ya la poderosa Buenos Aires, sino otra ciudad que por entonces estaba constituyéndose como el segundo polo más importante de distribución del país: Rosario. Los vínculos que Del Conte estableció, con las empresas distribuidoras en ascenso de este nuevo centro de abastecimiento, resultan claves para comprender el acelerado proceso de recambio experimentado durante la etapa final de la Gran Guerra en torno a la importación de películas extranjeras en el país, que culminó con la entronización definitiva del cine hollywoodense y de sus poderosas majors en los años veinte, pero que en el período estudiado se vivió como un germen de nuevas oportunidades de desarrollo local, incluso en lugares aparentemente tan alejados como las provincias del norte. Es que las por momentos desmesuradas aspiraciones de Del Conte deben medirse en el contexto histórico particular en el que le tocó actuar y que su valioso testimonio ayuda a reconstruir: se trata de un momento bisagra de la industria del cine en la Argentina en el que, en definitiva, un joven entusiasta y aventurero de veinte años podía imaginar para sí un horizonte de progreso que al mismo tiempo fuera compatible con el destino posible de todo un país.

\section{Referencias bibliográficas}

Broitman, A. y Samela, G. (2016). "Del celuloide al papel. Las publicaciones cinéfilas en la Argentina" En: González, H. y Rinesi, E. (comp.). Decorados. Apuntes para una historia social del cine argentino, reedición ampliada. La Plata: Caterva, pp. 293-313.

Brunetti, R. A. (2016). Cien años de Cine en Tucumán (1916-2016). San Miguel de Tucumán: Ediciones del Parque, 2016.

Colombres, N. E. y Piñero, J. (1901). Guía Ilustrada de Tucumán para el viajero. Buenos Aires: Compañía Sud-Americana de Billetes de Banco.

Cuarterolo, A. (2019). "El cine histórico argentino durante el período silente: Dos modelos estéticos e ideológicos en pugna", Vivomatografías. Revista de estudios sobre precine y cine silente en Latinoamérica, n. 5, pp. 233-276.

Del Conte, A. C. (1939). Formulario fotográfico. Buenos Aires: Biblioteca fotográfica de la revista Correo Fotográfico Sudamericano.

Friedman, J. (1952). "Alejandro C. Del Conte (1897-1952)", Correo Fotográfico Sudamericano, n. 678, 15 de abril, pp. 22-23.

Jelicié, E. (2018). "Entre la muerte y la risa. La circulación de los films de guerra en la Argentina y la figura de Max Linder (1914-1918)", Vivomatografías. Revista de estudios sobre precine y cine silente en Latinoamérica, n. 4, pp. 8-47.

Maldonado, L. (2006). Surgimiento y configuración de la crítica cinematográfica en la prensa argentina (1896-1920). Buenos Aires: iROJO.

Páez de la Torre, C. (2018). "El venerable teatro Belgrano", La Gazeta de Tucumán, 30 de diciembre. 
Paranaguá, P. A. (1993). “Amérique latine”, Cinéma Action, n. 69, dossier especial "Les revues de cinéma dans le monde", pp. 165-170.

Polacow, J. (1952) “Alejandro C. Del Conte (1897-1952)”, Boletín Foto-Cine, n. 71-72, pp. 8-9 y 31.

Schvarzer, J., Regalsky; T. Gómez. (comp.). (2007). Estudios sobre la historia de ferrocarriles argentinos 1857-1940. Buenos Aires: Universidad de Buenos Aires.

\section{Fuentes citadas}

Acosta, Edmundo, “A última hora”, Film Gráfico n. 12, 25 de agosto de 1917, p. 4.

"Alejandro Del Conte filma una película para la S.A.C.H.A. Manzanera”, El Mundo, 15 de agosto de 1931

"Carta de Alfredo Maubrigades (Rosario) a Alejandro Del Conte (Tucumán)", 22 de abril de 1918, CIFHA.

"Carta de Alfredo Maubrigades-North American Films Service (Córdoba) a Alejandro Del Conte (Tucumán), 12 de abril de 1918, CIFHA.

"Carta de Eduardo Grignolino (Tucumán) a Alejandro Del Conte (Buenos Aires)”, 13 de mayo de 1918, CIFHA

"Carta de Eduardo Grignolino (Tucumán) a Alejandro Del Conte (Buenos Aires)", 27 de mayo de 1918, CIFHA.

"Carta de Eduardo Grignolino (Tucumán) a Alejandro Del Conte (Buenos Aires)", 4 de junio de 1918, CIFHA.

"Carta de Eduardo Grignolino (Tucumán) a Alejandro Del Conte (Buenos Aires)", 13 de julio de 1918, CIFHA.

"Carta de Eduardo Manella (Buenos Aires) a Alejandro Del Conte (Tucumán)", 14 agosto de 1916, CIFHA.

"Carta de Juan Pujol (Santiago del Estero) a Alejandro Del Conte (Tucumán)", 9 de enero de 1918, CIFHA.

"Carta de Juan Pujol (Santiago del Estero) a Alejandro Del Conte (Tucumán)", 14 de enero de 1918, CIFHA.

"Carta de Juan Pujol (Santiago del Estero) a Alejandro Del Conte (Tucumán)", 3 de marzo de 1918, CIFHA.

"Carta de Juan Pujol (Santiago del Estero) a Alejandro Del Conte (Tucumán)", 8 de abril de 1918, CIFHA.

“Carta de la Compañía de Roberto Natalini (Rosario) a Alejandro Del Conte (Tucumán)”, 13 de abril de 1918, CIFHA.

“Carta de Manuel Brugo-Coop. Biográfica (Buenos Aires) a Alejandro Del Conte (Tucumán)", 5 de diciembre de 1917, CIFHA.

"Carta de Manuel Brugo (Buenos Aires) a Alejandro Del Conte (Tucumán)”, 12 de abril de 1918, CIFHA.

“Carta de Miguel Lustozzi (Tucumán) a A. Del Conte (Buenos Aires)”, 16 de mayo de 1918, CIFHA.

“Carta de Milá Boqué-Coop. Biográfica (Buenos Aires) a Alejandro Del Conte (Tucumán)", 25 de marzo de 1918, CIFHA. 
Cuarterolo y Jelicié. Hacia la conquista del Norte: el proyecto pionero de Film Gráfico y las batallas por...

“Carta de Raúl Massini-Cooperativa Biográfica (Buenos Aires) a Alejandro Del Conte (Buenos Aires)", 3 de agosto de 1917, CIFHA.

"Carta del Director de Cine Mundial (Nueva York) al Director de Film Gráfico (Tucumán)", 31 de enero de 1918, CIFHA.

“Cinema”, Film Gráfico, n. 19, 13 de octubre de 1917, p. 2.

"Confiterías con cine y el gremio biografista", Film Gráfico n. 20, 24 de noviembre de 1917, p. 5.

"Contrato entre Julio Alberto Castillo y A. Del Conte por alquiler del Teatro Belgrano", Tucumán, 15 de enero de 1917, CIFHA.

"De Córdoba", Excelsior, n. 131, 28 de agosto de 1916.

"El Belgrano. Su reapertura", Film Gráfico n. 7, 21 de abril de 1917, p. 2.

"El compañero Grignolino. Su renuncia”, Film Gráfico, n. 6, 17 de marzo de 1917

"El problema de las confiterías", Film Gráfico n. 15, 15 de septiembre de 1917, p. 1.

"Film Gráfico. Su nuevo carácter", Film Gráfico, n. 20, 24 de noviembre de 1917, p. 1.

"Film Gráfico", La Película, n. 19, 1 de febrero de 1917.

"Habla el administrador", Film Gráfico, n. 2, 10 de febrero de 1917, p.1.

"Juan José”, Film Gráfico, n. 15, 15 de septiembre de 1917, p. 1.

“'La barra de Taponazo' reproduce ambientes de cine y de sport”, Noticias Gráficas, 10 de septiembre de 1914

“'La barra de cañonazo' (sic) titulase una nueva cinta local”, La Razón, 15 de agosto de 1931

"La barra de cañonazo (sic), producción nacional", El Exhibidor, 30 de agosto de 1931

"La barra de Taponazo", El Heraldo del Cinematografista, n. 63, 14 de septiembre de 1932, p. 274

“La Cinematográfica Rosarina”, Film Gráfico, n. 7, 21 de abril de 1917, p. 2.

"La huelga ferroviaria y las remesas de cintas", Film Gráfico, n. 11, 18 de agosto de 1917 , p. 1.

"La North American Film Service. Su programa invade la zona”, Film Gráfico, n.10, 11 de agosto de 1917, p. 1.

"La Sudamericana y la North American Films Service”, Film Gráfico, n. 7, 21 de abril de 1917 , p. 1.

"La temporada", Film Gráfico, íbid., p. 2.

"La vida real y el biógrafo", Film Gráfico, n. 7, 21 de abril de 1917, p. 2

"La vuelta al redil", Film Gráfico n. 23, 29 de diciembre de 1917, p. 5.

"Las cintas en series", Excelsior, n. 200, 1 de enero de 1918, p. 68.

"Las patas de la sota", Film Gráfico n. 13, 1 de septiembre de 1917, p. 2.

"Lector", Film Gráfico. Revista Semanal Cinematográfica del Norte de la República, n.1, 21 de enero de 1917 , p. 1.

"Los niños y el cinematógrafo", Film Gráfico, n. 15, 15 de septiembre de 1917, p. 1

Magnani Tedeschi, S. "El Cinematógrafo y el americanismo", Film Gráfico, n. 23, 29 de diciembre de 1917, p. 6.

Natalini, Roberto, "Campo neutral”, Cinema Star, n. 147, 22 de junio de 1921, p. 4.

"Natalini y Cía. Instalación de sus tareas", Excelsior, n. 234, 4 de septiembre de 1918, p. 7.

"Nosotros", Film Gráfico, n. 19, 3 de octubre de 1917, p. 1. 
"Nosotros", Film Gráfico, n. 7, 21 de abril de 1917, p. 1.

"Nosotros", La Película, n. 28, 5 de abril de 1917, p. 1.

"Notas de Chile. Cómo se ha hecho la película 'Alma Chilena", Film Gráfico, n. 13, 1 de septiembre de 1917 , p. 2.

"Noticias de la pantalla", Cine Mundial, n.7, vol. 2, julio 1918, p. 407.

"Nuestro exadministrador", Film Gráfico, n. 14, 8 de septiembre de 1917.

"Nuevo administrador", Film Gráfico, n. 6, 17 de marzo de 1917

"Nuevo formato", Film Gráfico, n. 14, 8 de septiembre de 1917, p.4.

"Palabras de aliento", Film Gráfico, n. 2, 10 de febrero de 1917, p. 1.

"Periodismo", La Película, n. 112, 14 de noviembre de 1918, p. 18.

“Periodismo", La Película, n. 81, 12 de abril de 1918, p. 9.

"Periodismo", La Película, n. 87, 23 de mayo de 1918, p. 19.

"Publicidad de Tucumán Film”, Film Gráfico, n. 1, 20 de enero de 1917, p. 4.

Pujol, J. "El cinematógrafo", Film Gráfico, n. 7, 21 de abril de 1917, p. 4

"Recibimos", Film Gráfico, n. 15, 15 de septiembre de 1917, p. 4.

"Resultado de las denuncias de Orti", Film Gráfico n. 14, 8 de septiembre de 1917, p. 2.

"Se dio a conocer la película nacional "La barra de Taponazo", La Prensa, 10 de septiembre de 1914.

“Se estrenó la película 'La barra de Taponazo'. Un nuevo esfuerzo de la cinematografía nacional", La Nación, 11 de septiembre de 1932

"Seis mil pesos", Film Gráfico, n. 6, 17 de marzo de 1917, p. 2.

Señor X., "El Cinematógrafo. Proyecciones y alcance", Film Gráfico, n. 14, 8 de septiembre de 1917, p. 1

"Smart Palace", Excelsior, n. 126, 19 de julio de 1916, p. 19.

"Telegrama de Cooperativa Biográfica (Buenos Aires) a Alejandro Del Conte (Tucumán)", 7 de marzo de 1918, archivo del CIFHA.

“Telegrama de Genovesi (Tucumán) a Alejandro Del Conte (Santiago del Estero)”, 28 de enero de 1918, CIFHA.

“Telegrama de Juan Pujol (Santiago del Estero) a Alejandro Del Conte (Tucumán)”, 20 de enero de 1918, CIFHA.

"Un Administrador que nos estafa", Film Gráfico, n. 10, 11 de agosto de 1917

“Un año más”, Film Gráfico, n. 23, 29 de diciembre de 1917, p. 4.

"Un verdadero acontecimiento. La North American Film Service entre nosotros", Film Gráfico, n. 9, 2 de junio de 1917, p. 1

"Varias cintas prepara la Manzanera, La Opinión, 15 de agosto de 1931

"Viaje de Acosta y Di Niro a Rosario", Film Gráfico, n. 12, 25 de agosto de 1917, p. 2. 